Check for updates

Cite this: Chem. Sci., 2019, 10, 9626

๑ All publication charges for this article have been paid for by the Royal Society of Chemistry

Received 18th August 2019

Accepted 3rd October 2019

DOI: $10.1039 / c 9 s c 04118 d$

rsc.li/chemical-science

\section{Electrochemically switchable rotaxanes: recent strides in new directions}

\author{
Hendrik V. Schröder (D) $\dagger^{\star}$ and Christoph A. Schalley (D)
}

Are they still electrifying? Electrochemically switchable rotaxanes are well known for their ability to efficiently undergo changes of (co-)conformation and properties under redox-control. Thus, these mechanically interlocked assemblies represent an auspicious liaison between the fields of molecular switches and molecular electronics. Since the first reported example of a redox-switchable molecular shuttle in 1994, improved tools of organic and supramolecular synthesis have enabled sophisticated new architectures, which provide precise control over properties and function. This perspective covers recent advances in the area of electrochemically active rotaxanes including novel molecular switches and machines, metal-containing rotaxanes, non-equilibrium systems and potential applications.

\section{Introduction}

Rotaxanes, a class of mechanically interlocked molecules, consist in their most basic form of a macrocyclic wheel threaded on a linear axle molecule. ${ }^{1}$ Bulky stopper groups placed at the ends of the molecular thread prevent deslipping of the wheel. Encouraged by synthetic advances made during the last decades, for example in template synthesis, ${ }^{2-4}$ self-sorting ${ }^{5,6}$ or

Institut für Chemie und Biochemie, Freie Universität Berlin, Takustr. 3, 14195 Berlin, Germany. E-mail: hendrik.schroeder@fu-berlin.de

$\dagger$ Present address: Department of Chemical and Biological Engineering, Princeton University, Princeton, New Jersey 08544, USA. dynamic combinatorial chemistry, ${ }^{7-9}$ complex (supra)molecular architectures in a large structural complexity and variety ${ }^{10,11}$ have become more easily accessible. Conformational flexibility and dynamic nature of rotaxanes, given by the mechanical bond between their components, make them perfectly suited to undergo substantial structural changes when manipulated by external stimuli. ${ }^{12,13}$ Based on that, bi- and multi-stable rotaxanes arose as promising candidates for artificial molecular switches and machines over the last decades. ${ }^{14-16}$

Electrochemically switchable rotaxanes bear functional groups, which can undergo reversible redox reactions. These rotaxanes provide (co-)conformational control and can reversibly generate large-amplitude molecular motions by

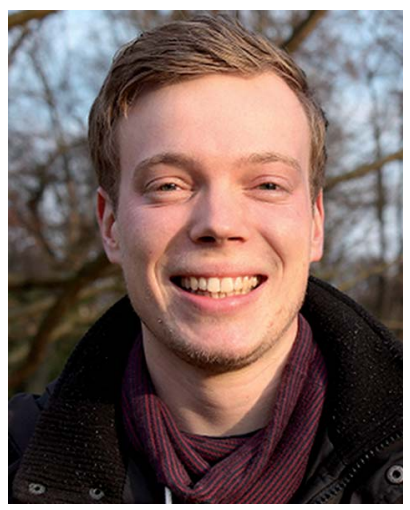

Dr Hendrik V. Schröder studied chemistry at Freie Universität in Berlin, Germany. Afterwards, he received a scholarship by the German Chemical Industry Fund (FCI) to prepare his doctoral thesis under the guidance of Prof. Dr Christoph A. Schalley. He worked in the fields of switchable rotaxanes and supramolecular electrochemistry. In autumn 2019, he started as postdoc funded by the German Research Foundation (DFG) in the group of Prof. A. James Link at Princeton University, USA, with focus on mechanically interlocked peptides. His current research interests include intertwined molecules, molecular switches and machines, organic synthesis, and electrochemistry.

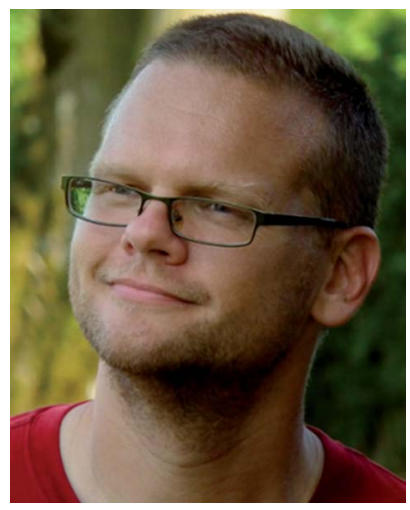

Christoph Schalley studied chemistry at the University of Freiburg/Germany and graduated in 1993 from the Technical University Berlin. In his PhD work with Helmut Schwarz at $T U$ Berlin, he received his thorough education as a mass spectrometrist and gas-phase chemist. After postdoctoral work on supramolecular chemistry with Julius Rebek, Jr. at The Scripps Research Institute, La Jolla/USA, he combined both topics when he started his own research group as a habilitand at the University of Bonn. In 2005, he was appointed professor of organic chemistry at Free University Berlin. Meanwhile the Schalley group's research topics are diverse and comprise supramolecular chemistry in the gas phase as well as in solution and at interfaces. 
electrochemical stimuli. In other words, they can convert electrochemical energy into directed movements at the molecular scale. Electrochemical energy is considered to be a simple, "clean" (no chemical waste production), selective and fast way to initiate molecular switching processes. ${ }^{17,18}$ Electrochemistry also offers a rich toolbox of methods to probe structural and electronic properties of even complex supramolecular ensembles. ${ }^{19}$ Valuable information including a qualitative and quantitative assessment of the available oxidation states, ${ }^{20}$ electrochemical reaction mechanisms, ${ }^{21}$ diffusion constants, ${ }^{22}$ orbital energies, ${ }^{23}$ and much more can be extracted by electroanalytical methods. Additionally, methods of supramolecular electrochemistry ${ }^{24}$ provide rare access to thermodynamic and kinetic parameters of intramolecular (co-)conformational changes, which are often out of the scope of classical analytic methods in supramolecular chemistry. ${ }^{25,26}$

Exactly 25 years ago, the first electrochemically switchable molecular shuttle based on a two-station rotaxane has been reported, ${ }^{27}$ raising high hopes for the field of molecular switches and machines. Although these rotaxanes are among pioneering examples, systems have evolved from rather simple molecular shuttles to advanced supramolecular architectures bringing multiple functions together. Recent systems come with a precise electrochemical control of molecular motions, properties and functions. Additionally, new types of metalorganic rotaxanes provide potential applications as catalysts, sensors, and single-molecule electronic devices. Undoubtedly,

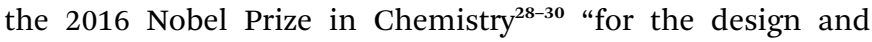
synthesis of molecular machines" marks the outstanding significance of these developments. On the other hand, it redirects the trajectory of the field of rotaxanes towards more functionalized and applicable systems.

Numerous excellent overviews covering switchable rotaxanes, ${ }^{1,31,32}$ metal-containing rotaxanes ${ }^{2,33,34}$ and electrochemically active supramolecular systems ${ }^{24,35,36}$ have been published. This perspective is focused on recent developments of redox-active (pseudo)rotaxanes-especially those reported after the 2016 Nobel Prize-and applications arising from their electrochemical activity on the basis of a non-exhaustive list of illustrative examples. In particular, this summary gives a differentiated view on recent advances beyond classical molecular shuttles. It covers (i) rotaxanes generating molecular motions; (ii) metal-containing rotaxanes; (iii) applications of rotaxanes including sensing, catalysis, molecular electronics and molecular machines; and (iv) non-equilibrium systems.

\section{Rotaxanes generating molecular motions}

\section{Fundamentals of redox-controlled molecular shuttles}

Archetypical examples of electrochemically switchable rotaxanes are two-station molecular shuttles, ${ }^{27}$ in which the position of a wheel on a molecular thread can be manipulated by reduction or oxidation (Fig. 1). Electroanalytic methods, such as commonly applied cyclic voltammetry (CV), can provide qualitative evidence for co-conformational changes through altered half-wave $\left(E_{1 / 2}\right)$ or peak $\left(E_{\mathrm{p}}\right)$ potentials and can even quantify the distribution of isomers in different redox-states. ${ }^{24,35}$ The isomer distribution is given by the dimensionless co-conformational equilibrium constant $K_{\mathrm{x}}$ (Fig. 1, eqn (1)) for each redox-state (x). The efficiency of a molecular switch can be expressed as the binding enhancement of a station which reflects the ratio between $K_{\mathrm{x}}$ values in two redox-states (Fig. 1, eqn (2)). In recent years, supramolecular construction motifs have been continuously optimized to gain more control over co-conformational switching. ${ }^{37}$

Electrochemical experiments (e.g. $\mathrm{CV})$ at different scan rates or chrono methods can additionally help to identify reversibility, to elucidate reaction mechanisms, and to investigate the kinetics ${ }^{38}$ of conformational changes. Furthermore, digital simulations ${ }^{39}$ are

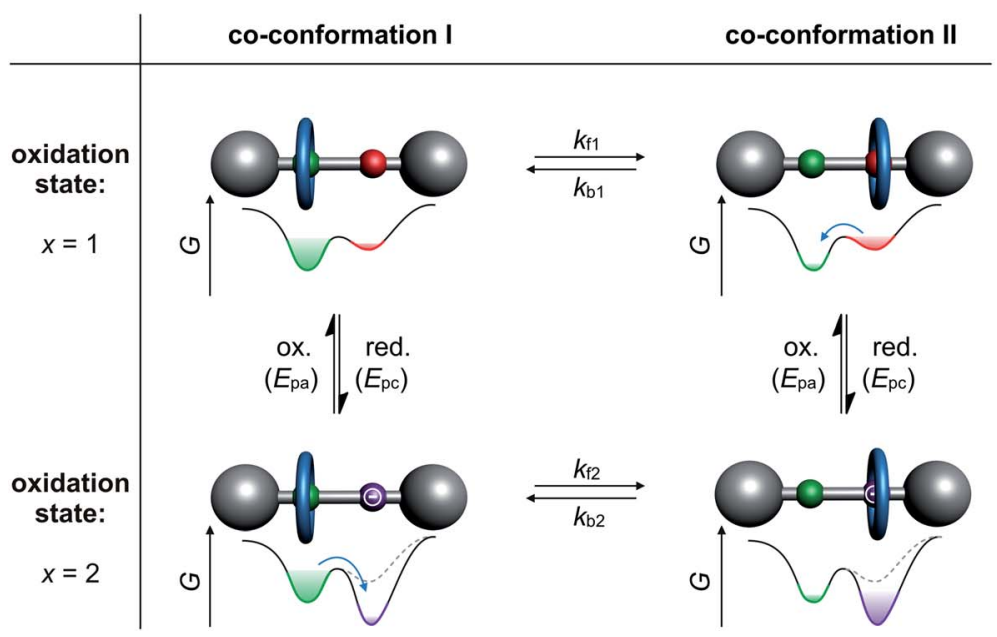

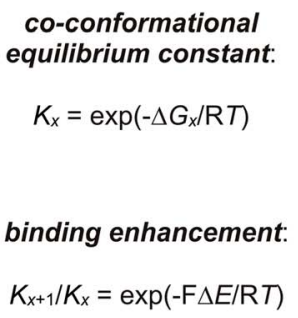

kinetic rate constants:

$$
K_{x}=k_{\mathrm{fx}} / k_{\mathrm{bx}}
$$

Fig. 1 A general square scheme for an electrochemically switchable [2]rotaxane. It illustrates co-conformational isomers and the corresponding energy landscapes of wheel translation in two stable redox-states ( $x=1$ or 2$)$. The eqn (1)-(3) describe the thermodynamics and kinetics of the switching processes, where $G_{x}$ is the Gibbs free energy in a given oxidation state, $k$ a first-order rate constant, $F$ the Faraday constant, $T$ the temperature, $\Delta E$ a potential difference between two redox-reactions and $R$ the ideal gas constant. 
often used as a complementary tool not only to predict voltammetric responses of supramolecular systems but also to fit experimental data. Digital simulation provides access to thermodynamic and kinetic parameters $\left(K_{\mathrm{x}}, k_{\mathrm{fx}}\right.$ and $\left.k_{\mathrm{bx}}\right)$ as a selfconsistent set of values (Fig. 1, eqn (3)). Naturally, the accuracy of the derived values depends on the correct choice of reaction mechanism, the quality of experimental data and the input variables. Improvement in accuracy can be achieved by comparing with data, for example, diffusion or binding constants derived from independent analytical methods or model systems.

For instance, an electrochemically controllable molecular shuttle with a highly selective co-conformational distribution was reported in a 2003 landmark publication of Leigh, Paolucci and co-workers. ${ }^{\mathbf{4 0}}$ The thread of hydrogen-bonded [2]rotaxane $\mathbf{1}$ (Fig. 2) bears a naphthalimide unit, which serves simultaneously as a stopper for the wheel and as a redox-active recognition side. In the neutral state, the tetralactam wheel preferably encircles the diamide over the naphthalimide station. Electrochemical oneelectron reduction generates a stable naphthalimide radical anion $\left(E_{\mathrm{pc}}=-1.40 \mathrm{~V} v s . \mathrm{Fc} / \mathrm{Fc}^{+}, \mathrm{Fc}=\right.$ ferrocene), which is now a more favorable hydrogen bond acceptor. By CV experiments and digital simulations, a binding enhancement of $>10^{8}$ for the naphthalimide station after reduction was determined leading to a translation of the wheel towards it. In comparison to the free thread, re-oxidation $\left(E_{\mathrm{pa}}=-0.89 \mathrm{~V}\right)$ is anodically shifted reflecting stabilization of the radical anion by the hydrogenbonded wheel. Variable-temperature experiments in THF revealed the kinetic parameters $\Delta H^{\star}=59 \mathrm{~kJ} \mathrm{~mol}^{-1}$ and $\Delta S^{\star}=$ $36 \mathrm{~kJ} \mathrm{~mol}^{-1}$ for wheel translation from the diamide to the naphthalimide station after reduction, resulting in a shuttling time of $\sim 50 \mu \mathrm{s}$ at room temperature. In a recent report, the shuttling mechanism was studied in more detail by transient two-dimensional infrared spectroscopy. ${ }^{41}$

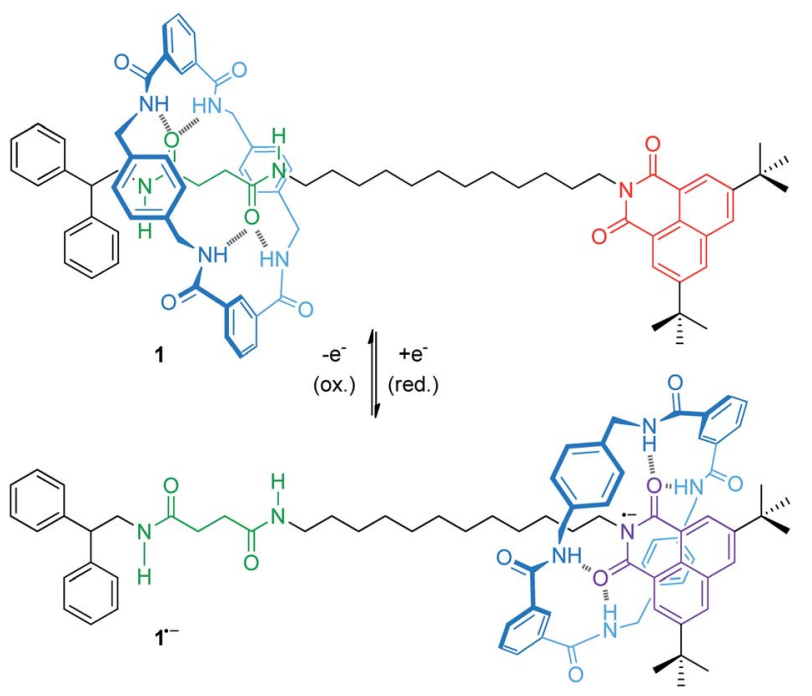

Fig. 2 Electrochemically switchable molecular shuttle 1. In the neutral state, the tetralactam wheel preferably encircles the diamide station. One-electron reduction to the $1^{\cdot-}$ state moves the wheel to the naphthalimide radical anion site.

\section{Rotaxane shuttles enabling rare interactions}

The mechanical bond prevents dissociation of non-covalently bound molecular entities and can stabilize interactions, which are otherwise unfavorable. ${ }^{42}$ Thus, rotaxanes offer an opportunity to study these rare interactions between subcomponents or even utilize them for (co-)conformational control.

For example, Stoddart and co-workers recently reported on the tristable [2]rotaxane $2^{6+}$ (Fig. 3) with three different recognition sites on the thread, namely two triazoles, two tetrafluorobenzenes and one bipyridinium unit. ${ }^{\mathbf{4 3}}$ In the initial state, the quadruply charged cyclobis(paraquat- $p$-phenylene) $\left(\mathrm{CBPQT}^{4+}\right)$ wheel preferably encircles one of the relatively $\pi$ electron-rich triazoles by forming a donor-acceptor complex. The wheel's binding affinity can then be altered by stepwise reduction. Cyclovoltammetry reveals an initial two-electron reduction $\left(E_{\mathrm{pc} 1}=-0.14 \mathrm{~V}\right.$ vs. $\left.\mathrm{Ag} / \mathrm{AgCl}\right)$ to $2^{\mathbf{2 \cdot / 4 +}}$ closely followed by a one-electron reduction $\left(E_{\mathrm{pc} 2}=-0.22 \mathrm{~V}\right)$. The resulting tri-radical species $2^{3(\cdot+)}$ is stabilized by radical-pairing interactions between the doubly reduced wheel $\mathrm{CBPQT}^{2(\cdot+)}$ and the singly reduced bipyridinium station. A further threeelectron reduction $\left(E_{\mathrm{pc} 3}=-0.69 \mathrm{~V}\right)$ to $2^{(\mathbf{0})}$ neutralizes wheel and bipyridinium station. Now, the $\mathrm{CBPQT}^{(0)}$ ring migrates to one of the $\pi$-electron-poor tetrafluorobenzene moieties. This supramolecular charge-transfer complex-which is enabled through spatial pre-organization of the wheel-is rather weak and cannot be easily studied in "the context of a host-guest complex", ${ }^{43}$ unless stabilized by a mechanical bond.
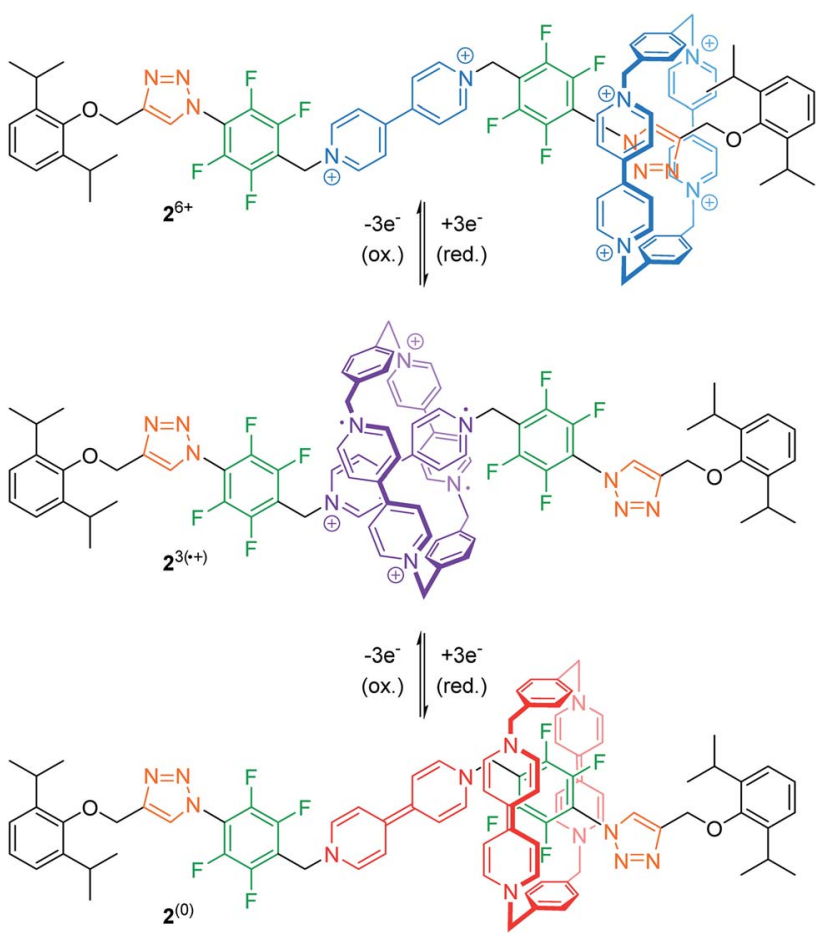

Fig. 3 Tristable [2] rotaxane $2^{6+}$ in its three different redox-states and resulting co-conformations. The unusual $\mathrm{CBPQT}^{(0)} /$ tetrafluorobenzene charge-transfer complex is stabilized by the mechanical bond. 
(a)
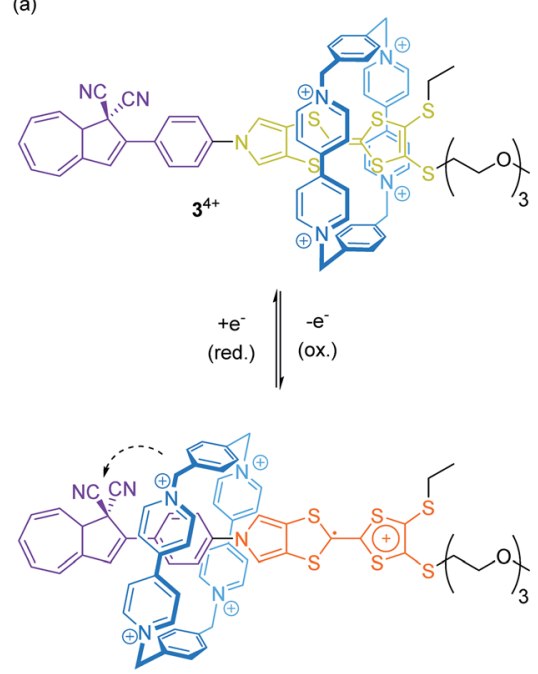

(b)

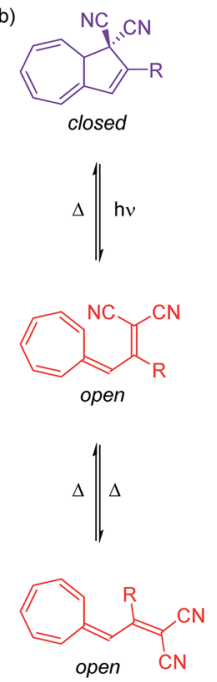

Fig. 4 (a) Redox-active [2]rotaxane $3^{4+}$ bearing a photo- and thermoswitchable dihydroazulene unit as stopper. The dashed arrow illustrates through-space interactions between $\mathrm{CBPQT}^{4+}$ wheel and dihydroazulene site. (b) Photo- and thermoswitching of the 1,1dicyano-dihydroazulene moiety.

Rare through-space interactions also play a role in the orthogonally switchable CBPQT ${ }^{4+}$-rotaxane recently reported by Jeppesen, Nielsen and co-workers (Fig. 4a). ${ }^{44}$ The CBPQT ${ }^{4+}$ wheel of [2] rotaxane $\mathbf{3}^{\mathbf{4}^{+}}$is threaded on a redox-active monopyrrolo-tetrathiafulvalene axle, which is terminated on one side with a 1,1-dicyano-dihydroazulene moiety, a molecular photo- and thermoswitch (Fig. 4b). In both photoisomeric forms, the closed dihydroazulene and open vinylheptafulvene form, deslipping of the wheel is sterically hindered. The presence of the wheel anodically shifts both tetrathiafulvalene (TTF) oxidation potentials as compared to the free thread. However, the first oxidation already induces a movement of the wheel towards the dihydroazulene/phenylene site forming weak interactions between the cyano groups and the wheel's bipyridinium $\alpha$-protons. These rather weak interactions between wheel and axle significantly accelerate the thermal backconversion of the dihydroazulene switch (open to closed form) after photoirradiation.

Weak through-space interactions were also found to affect TTF redox-potentials of our recently reported rotaxane shuttles consisting of a TTF-decorated crown ether wheel and a neutral axle. $^{45}$ The $\mathrm{TTF}^{\mathrm{TTTF}}{ }^{\cdot+}$ oxidation was cathodically shifted compared to the free TTF-wheel, indicating significant stabilization of the $\mathrm{TTF}^{\cdot+}$ state by interactions between the mechanically bound axle and the $\mathrm{TTF}^{\circ+}$ moiety.

\section{Oligorotaxanes and daisy chain rotaxanes}

Linear main-chain oligo- and polyrotaxanes, in which several wheels are threaded on an axle, have been used as supramolecular scaffolds to generate large-amplitude motions. ${ }^{\mathbf{4 6}, 47}$ The resulting structural changes are reminiscent of molecular folding and contraction processes of biopolymers, e.g. protein folding or muscle contraction.

The Stoddart group presented an oligo[3]rotaxane, in which axle and wheels as a whole undergo an redox-triggered folding/ unfolding along the trajectory of the axle. ${ }^{48}$

Our lab recently reported on oligorotaxanes, in which interwheel distances can be controlled by radical-cation interactions between TTF-decorated wheels (Fig. 5a). ${ }^{49}$ In the initial state, the 24-crown-8 ether wheels of oligo[4] rotaxane $4^{3+}$ are bound to secondary ammonium stations by hydrogen bonding. Reversible oxidations of the wheels' TTF units weaken the wheel-axle interactions through counteracting Coulomb repulsion. As shown by electrochemistry, UV/Vis-NIR and electron paramagnetic resonance spectroscopy, the $\mathrm{TTF}^{*}+$ moieties can form inter-wheel mixed-valence $\left(\mathbf{4}^{\cdot / \mathbf{4}+}\right)$ and radical-cation $\left(4^{3 \cdot / 6+}\right)$ interactions, which consequently lead to a contraction of the ensemble in both redox-states. Further oxidation $\left(\mathrm{TTF}^{\cdot+}\right.$ to $\mathrm{TTF}^{2+}$ ) to the $\mathbf{4}^{\mathbf{9 +}}$ state creates strong charge repulsion between the $\mathrm{TTF}^{2+}$ units and leads to a maximization of the inter-wheel distances. The resulting accordion-like motion (Fig. 5b) is independent of the molecular thread and, thus, promising for the construction of piston-type rotaxane motors.

Electrochemically switchable daisy chain rotaxanes are ideal prototypes to generate a muscle-like contraction. Moulin and Giuseppone introduced a [c2] daisy chain rotaxane $\left(5^{4+}\right.$, Fig. 6) with two different endgroups, where the mechanical actuation is controlled by acid/base addition. ${ }^{50}$ The crown ether/

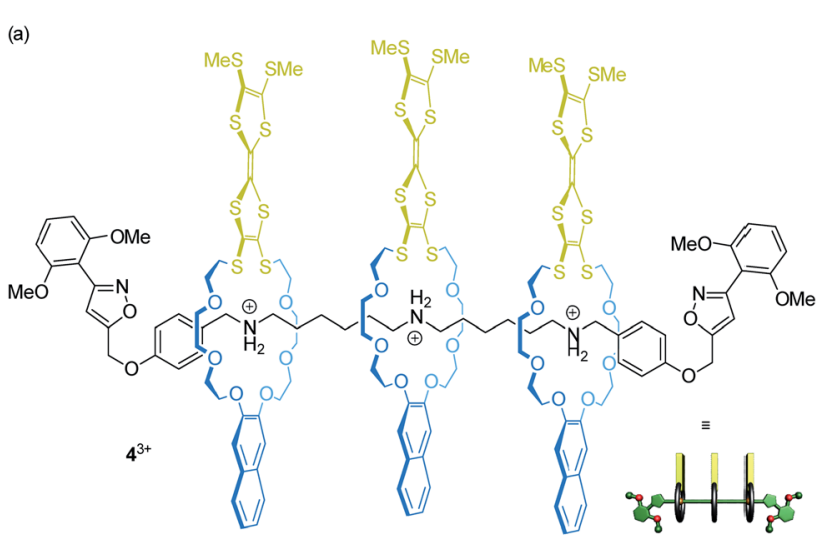

(b)

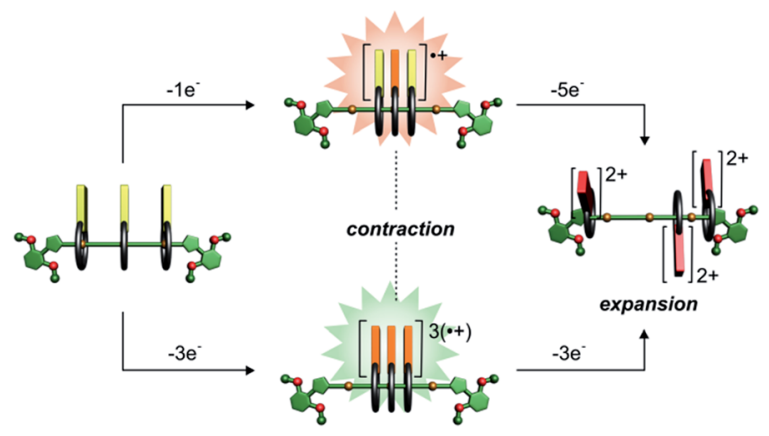

Fig. 5 (a) Structure of the electrochemically switchable oligo[4] rotaxane $4^{3+}$. (b) Graphical summary of the redox-controlled generation of an accordion-like contraction/expansion motion. Partly adapted with permission from ref. 49. Copyright (2019) John Wiley \& Sons. 


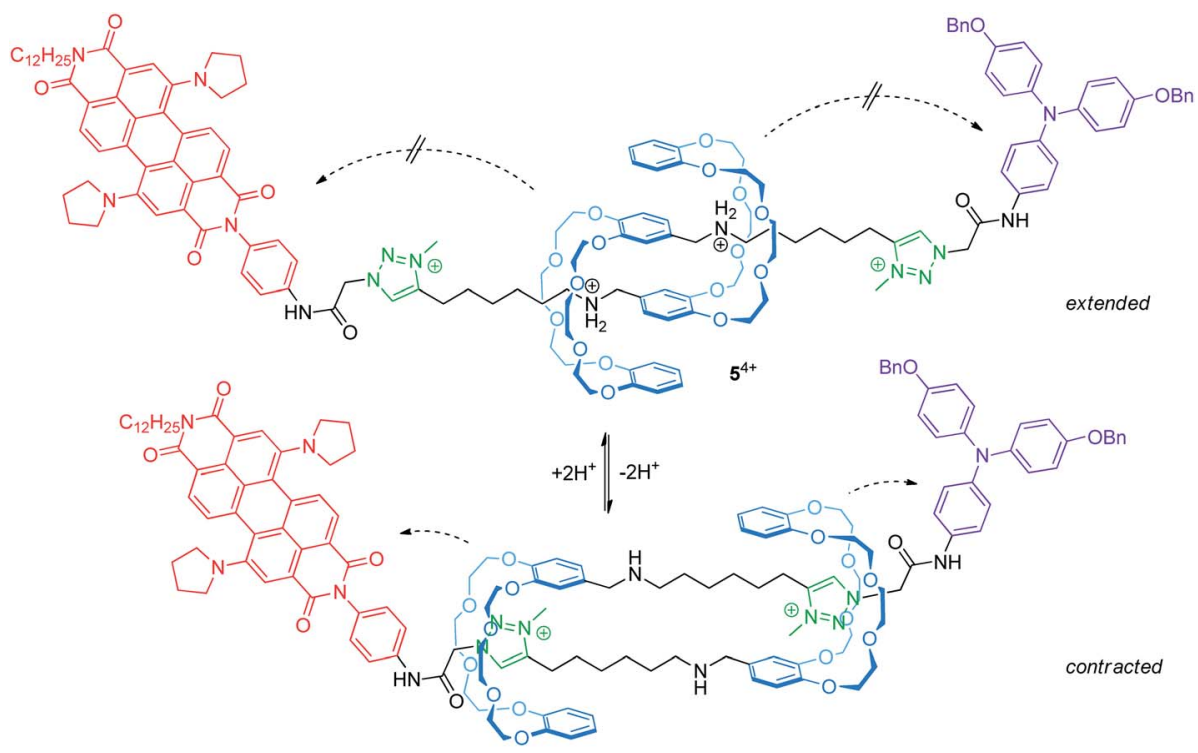

Fig. 6 Switching of the acid/base-responsive [c2] daisy chain rotaxane $5^{4+}$ between its extended and contracted form. Both forms show altered electrochemical properties. The dashed arrows illustrate electronic through-space interactions between the wheels and the redox-centers.

ammonium rotaxane is decorated with two redox-active stoppers, a 1,7-dipyrrolidinyl-substituted perylene diimide and a triarylamine unit. In the extended form (protonated), three reversible electrochemical processes are observed by cyclovoltammetry: a two-electron reduction $\left(E_{1 / 2}^{1}=-1.30 \mathrm{~V} v s . \mathrm{Fc} / \mathrm{Fc}^{+}\right)$ centered on the perylene diimide, an oxidation wave $(+0.19 \mathrm{~V})$ resulting from a superposition of two one-electron oxidations centered on the triarylamine and the perylene diimide and a second one-electron oxidation of the perylene diimide unit $(+0.31 \mathrm{~V})$. The cyclic voltammogram is a superposition of those of the corresponding individual reference compounds; thus, both redox-active groups are electrochemically unaffected in the extended form. In the contracted form (deprotonated), however, the two-electron reduction wave is broadened and the peak current of the re-oxidation is significantly decreased indicating a lower chemical stability. At the same time, the second oxidation of the perylene diimide unit is shifted to lower potentials. The authors have attributed both effects to the proximity of the crown ethers to the electro-active stoppers after contraction.

\section{Other types of redox-controlled motion}

Electrochemical control of wheel-axle interactions opens up possibilities for other types of controlled motion. For example, electrochemically switchable pseudorotaxanes consisting of redox-active threads and cyclodextrins $s^{51}$ or cucurbiturils ${ }^{52-54}$ as macrocyclic compounds have been used to create stimuli responsive polymers and materials.

Recently, Stoddart and co-workers built the pseudo[1] rotaxane $6^{6+}$ based on their well investigated $\mathrm{CBPQT}^{4+}$ wheel covalently attached to a viologen thread (Fig. 7a). ${ }^{55}$ Complex $6^{6+}$ efficiently switches between a rope-like and a lasso-type conformation upon reduction. CV and differential pulse voltammetry show that the first reduction wave $\left(E_{\mathrm{pc}}=-0.33 \mathrm{~V} v s\right.$. $\mathrm{Ag} / \mathrm{AgCl}$ ) is a combination of a two- and a one-electron reduction leading to triradical species $6^{3(\cdot+)}$. An anodic shift $\left(\Delta E_{\mathrm{pc}}=\right.$
$+0.10 \mathrm{~V}$ relative to a suitable control compound), indicates the stabilization of the self-inclusion conformation to result from the strong, intramolecular radical-pairing interactions between

(a)
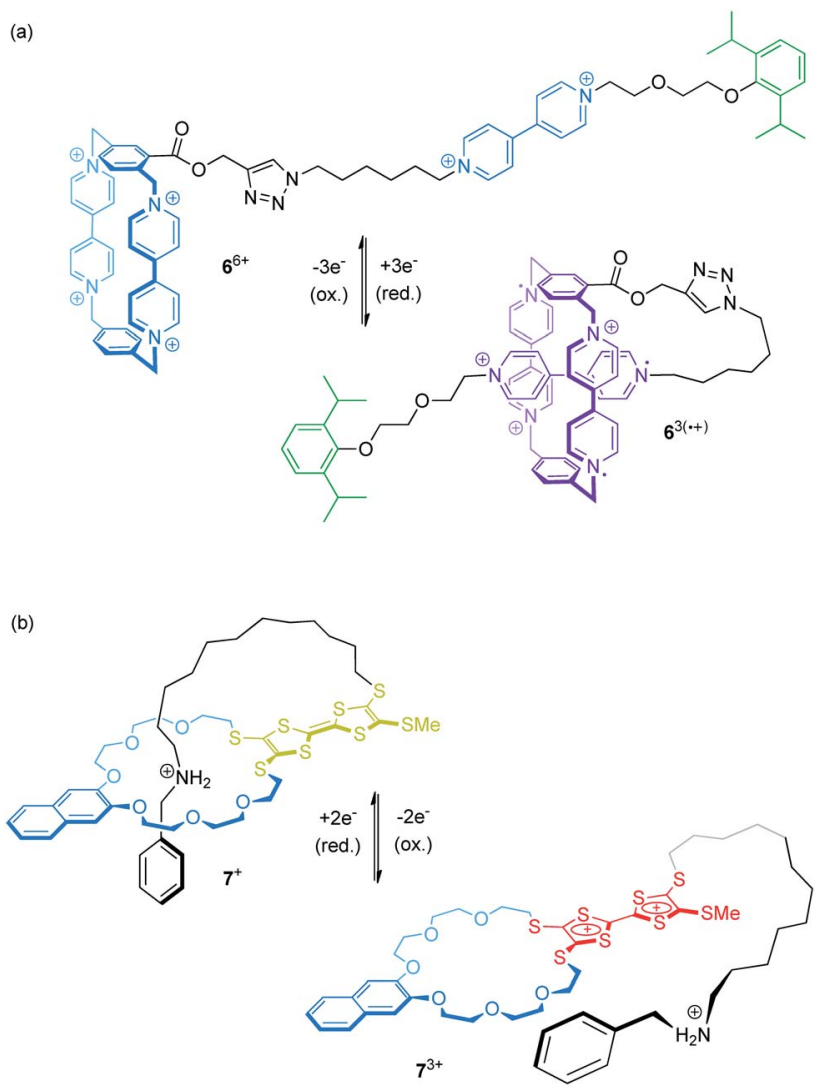

Fig. 7 Two examples for electrochemically controlled pseudo[1] rotaxanes which are convertible between a rope-like and a lasso-type conformation: (a) $6^{6+}$ undergoes self-inclusion after reduction, whereas (b) $7^{+}$is preferentially threaded in the initial state and unthreads upon oxidation. 
the $\mathrm{CBPQT}^{2(\cdot+)}$ wheel and the reduced thread. Supported by NMR, UV/Vis-NIR and crystallographic data, the authors suggest a "revolving-door mechanism" in which selfentanglement is initiated by rotation of the $p$-phenylene moiety in the wheel component.

We recently presented the redox-switchable pseudo[1]rotaxane $7^{+}$(Fig. 7b) based on a crown ether/ammonium motif which adopts a self-inclusion conformation when an incorporated TTF unit is neutral. ${ }^{56} \mathrm{CV}$ experiments and digital simulations demonstrate that stepwise oxidation of the TTF moiety generates charge repulsion in the assembly; thus, stepwise oxidation controls the conformational ratios between the threaded and non-threaded state.

Besides shuttling, controlling the rotation of wheels around an axle (pirouetting) is a worthwhile but challenging goal. ${ }^{33,57,58}$ Crown ether/ammonium [3]rotaxane $\mathbf{8}^{\mathbf{2 +}}$ which enables electrochemically controlled pirouetting (Fig. 8) was recently reported. ${ }^{59}$ The wheels are decorated with redox-switchable TTF units. A structurally similar control with only one TTF-wheel displays two reversible one-electron oxidations at $E_{1 / 2}^{1}=0.16 \mathrm{~V}$

(a)

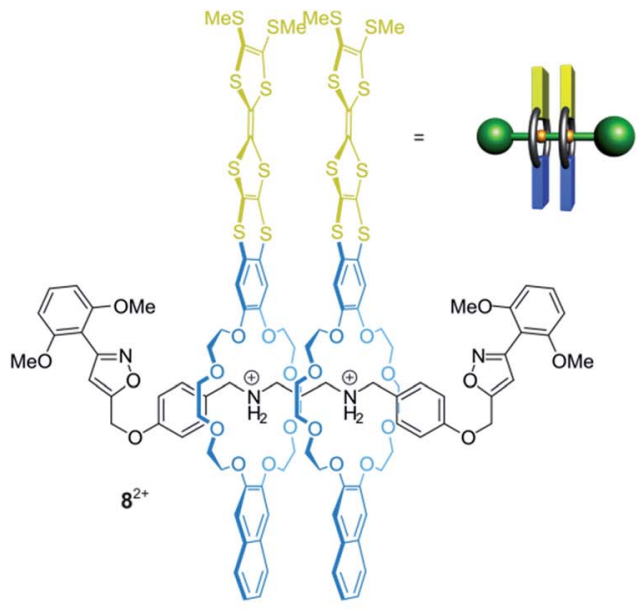

(b)
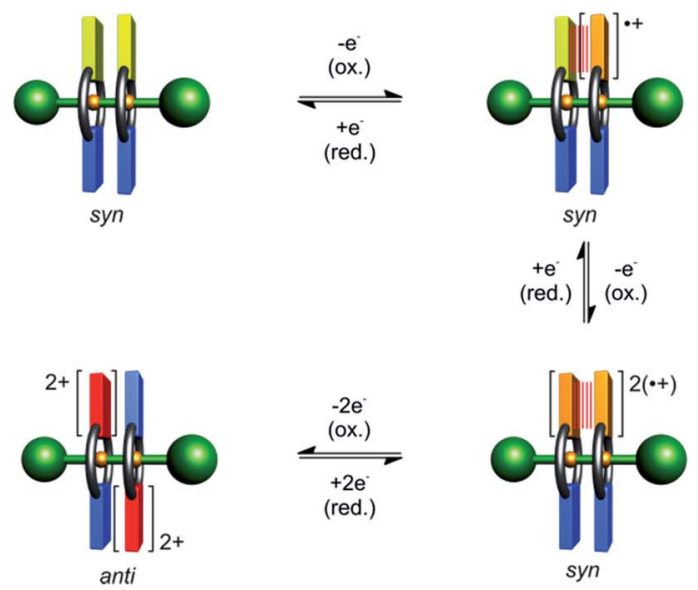

Fig. 8 (a) Electrochemically switchable crown ether/ammonium [3] rotaxane $8^{2+}$, which allows to control relative wheel pirouetting motions. (b) Graphical summary of the most-stable co-conformations of $8^{2+}$ in its four stable redox-states. and $E_{1 / 2}^{2}=0.40 \mathrm{~V} v s . \mathrm{Fc} / \mathrm{Fc}^{+}$for the $\mathrm{TTF} / \mathrm{TTF}^{\cdot+}$ and $\mathrm{TTF}^{\cdot+} / \mathrm{TTF}^{2+}$ transition, respectively. In contrast, rotaxane $\mathbf{8}^{\mathbf{2 +}}$ exhibits a splitting of the TTF/TTF ${ }^{\cdot+}$ wave $\left(E_{1 / 2}^{1}=0.08 \mathrm{~V}\right.$ and $\left.E_{1 / 2}^{2}=0.19 \mathrm{~V}\right)$ and a two-electron oxidation at $E_{1 / 2}^{3}=0.48 \mathrm{~V}$. The splitting indicates an intramolecular mixed-valence complex $\left(\mathrm{TTF}_{2}\right)^{\cdot+}$, whose stability is reflected in a comproportionation constant of $K_{\mathrm{c}}=73$. The second one-electron oxidation $E_{1 / 2}^{2}$ yields a stable radical-cation dimer $\left(\mathrm{TTF}^{\cdot+}\right)_{2}$, which was confirmed by electron paramagnetic resonance and UV/Vis-NIR spectroscopy. Supported by digital simulations and density functional theory, it could be shown that the wheels in the oxidation states 2TTF, $\left(\mathrm{TTF}_{2}\right)^{\cdot+}$ and $\left(\mathrm{TTF}^{\cdot+}\right)_{2}$ adopt a syn co-conformation, whereas an anti co-conformation is found for the $2 \mathrm{TTF}^{2+}$ state.

\section{Kinetics of redox-controlled molecular shuttles}

Great effort has been made in recent years to understand and control the kinetics of redox-induced translational motion in rotaxane shuttles. ${ }^{38}$

Lately, the dependence of the shuttling kinetics of an electrochemically switchable $\mathrm{CBPQT}^{4+}$-rotaxane on the electrolyte concentration was investigated by Jeppesen and co-workers. ${ }^{60}$ For electrochemical experiments, supporting electrolytes are frequently required in high concentrations to increase solution conductivity. It was found that tetraalkylammonium salts $\left(\mathrm{R}_{4} \mathrm{~N}^{+} \mathrm{X}^{-}\right)$in general lead to an increased switching rate, whereas the size of the $\mathrm{R}_{4} \mathrm{~N}^{+}$cation has no significant effect on wheel shuttling. However, a increased rate was observed when using $\mathrm{ClO}_{4}{ }^{-}$instead of $\mathrm{PF}_{6}{ }^{-}$as the electrolyte's anion.

The Stoddart group has recently investigated shuttling rates in a redox-switchable ring-in-ring rotaxane, where the axle itself incorporates a redox-active macrocycle. ${ }^{61}$ Electrochemically induced shuttling was found to be significantly slower compared to their previous systems. ${ }^{62}$ The slow motion results in an electrochemical hysteresis for switching as shown by $\mathrm{CV}$ and digital simulations. Furthermore, the slow shuttling could be used to characterize a diamagnetic tetraradical complex by ${ }^{1} \mathrm{H}$ NMR spectroscopy, whose lifetime is otherwise too short.

\section{Metal-containing rotaxanes}

Since Sauvage's seminal work ${ }^{\mathbf{3 3 , 6 3}}$ on $\mathrm{Cu}$-containing catenanes, metal-ligand interactions have always played a key role in the synthesis of mechanically interlocked molecules, for example in a templating pre-organization of the precursor molecules. ${ }^{34}$ More recently, the active template approach ${ }^{2}$ evolved, in which metal ions serve as templates and as mediators for the formation of mechanical bonds. However, metals are also integral subcomponents of rotaxanes bringing with them versatile properties and functions. Metals can serve as persistent redoxcenters, which change conformational or optoelectronic properties of a rotaxane with their oxidation state.

\section{Rotaxanes bearing covalently bound metal complexes}

The group of Korybut-Daszkiewicz reported recent progress on their switchable rotaxanes with a cyclidene/crown ether ${ }^{64}$ motif. Fig. 9 shows [2] rotaxane $\mathbf{9}^{\mathbf{4}}$ which consists of an axle with a 14- 


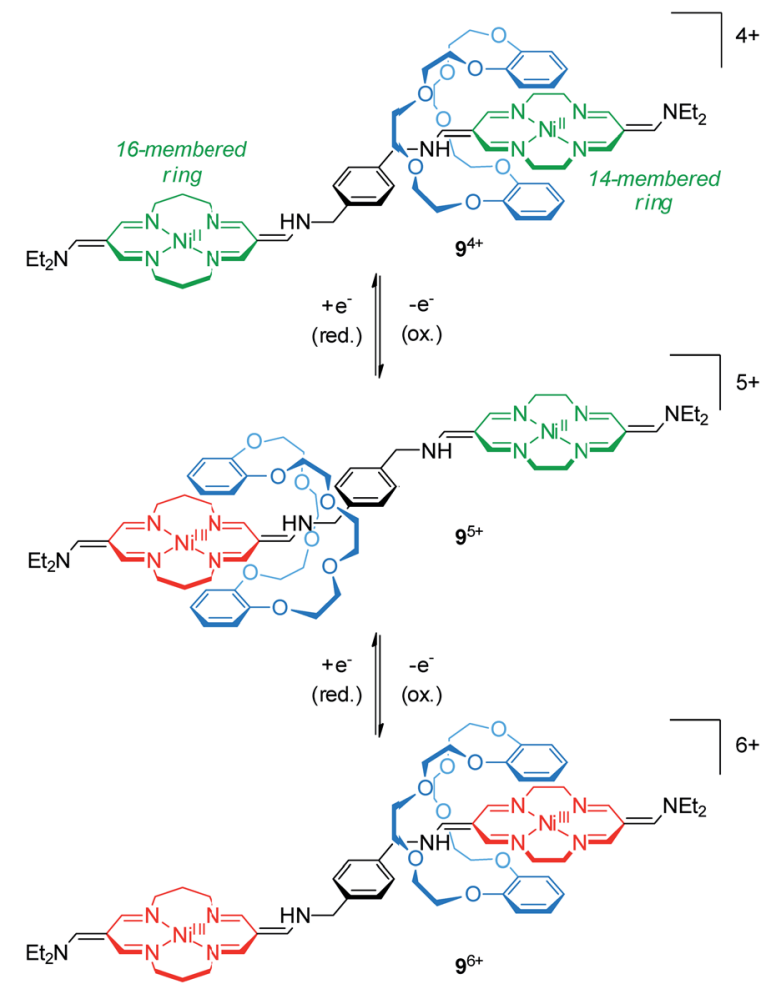

Fig. 9 Redox-controlled molecular shuttle $9^{4+}$ based on the cyclidene/crown ether motif in its three stable oxidation states $\left(\mathrm{Ni}^{\prime \prime} / \mathrm{Ni}{ }^{\prime \prime}\right.$, $\mathrm{Ni}{ }^{\prime \prime \prime} / \mathrm{Ni}^{\prime \prime}$ and $\mathrm{Ni}^{\mathrm{II}} / \mathrm{Ni}^{\mathrm{ill}}$ ).

and a 16-membered $\mathrm{Ni}^{\mathrm{II}}$-complexing tetraazamacrocycle and a threaded dibenzo-24-crown-8 wheel. ${ }^{65}$ In the initial state, the crown ether preferentially encircles the 14 -membered ring since it is a stronger electron acceptor. However, the 16-membered $\mathrm{Ni}^{\mathrm{II}}$ complex shows a less positive oxidation potential at $1.15 \mathrm{~V}$ vs. $\mathrm{Ag} / \mathrm{AgCl}$ as shown by differential pulse voltammetry. Oneelectron oxidation $\left(\mathrm{Ni}^{\mathrm{II}} / \mathrm{Ni}^{\mathrm{III}}\right)$ converts the 16 -membered ring to a better electron acceptor and the wheel translates to the $\mathrm{Ni}^{\mathrm{III}}$ binding site. Subsequent one-electron oxidation of the 14membered ring complex at higher potentials induces a reversed shuttling motion of the wheel. Interestingly, a splitting of the signal for the $\mathrm{Ni}^{\mathrm{II}} / \mathrm{Ni}^{\mathrm{III}}$ oxidation is observed indicating that wheel shuttling takes place on the time scale of the experiment.

The team of Ma synthesized a pH-controlled molecular shuttle based on a crown ether/ammonium [2] rotaxane. ${ }^{66}$ The crown ether macrocycle is decorated with a $\mathrm{Pt}^{\mathrm{II}}$ porphyrin moiety, which allows following wheel shuttling by changes of room temperature phosphorescence. Additionally, CV indicates electronic interaction between the $\mathrm{Pt}^{\mathrm{II}}$ porphyrin and a redoxactive viologen unit, which is additionally incorporated in the axle.

Delavaux-Nicot, Nierengarten, Maisonhaute and others have reported the pillar[5] arene rotaxane $\mathbf{1 0}$ bearing ten peripheral Fc units attached to the wheel to investigate electron transfer processes (Fig. 10) ${ }^{67}$ One of the stoppers is substituted with two lipoic acid esters, which allow grafting the rotaxane onto gold microelectrodes. In solution, CV and Osteryoung squarewave voltammetry showed a single ten-electron wave $\left(E_{1 / 2}=0.59\right.$ vs.

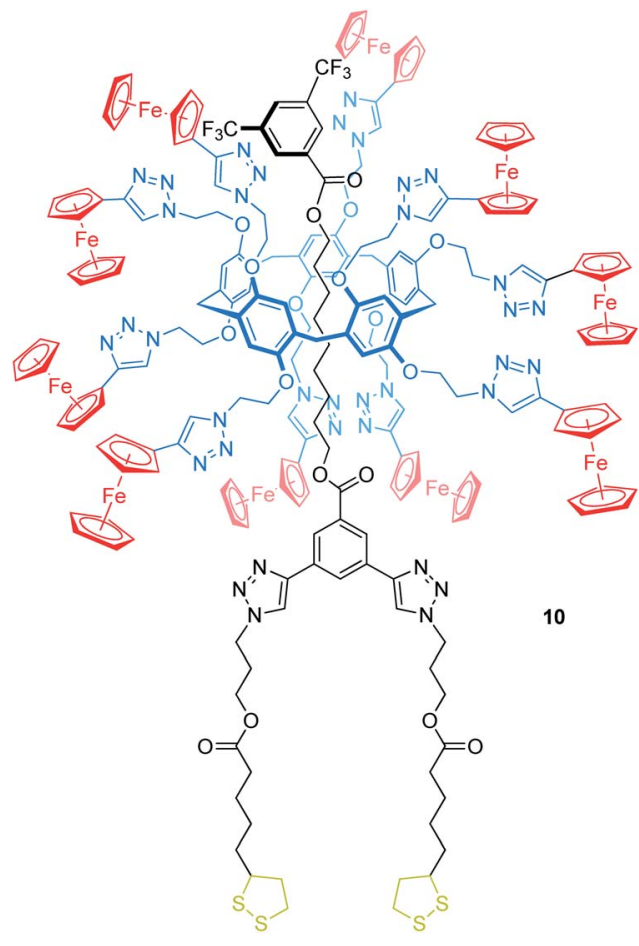

Fig. 10 Structure of the ferrocene-decorated rotaxane 10, which has been grafted onto a gold microelectrode.

SCE, SCE $=$ saturated calomel electrode) due to the $\mathrm{Fc} / \mathrm{Fc}^{+}$ oxidations. A set of control experiments confirmed that no other redox-process occurs in this potential window. After grafting the rotaxane onto a gold microelectrode, a self-assembled monolayer of $\mathbf{1 0}$ was probed by ultrafast voltammetry revealing the rates of electron transfer $k_{\mathrm{ET}}$ in dependence of different scan rates and surface coverages. A low coverage of $19 \mathrm{~nm}^{2}$ per molecule leads to a $k_{\mathrm{ET}}$ of $5.8 \times 10^{5} \mathrm{~s}^{-1}$, whereas a denser coverage decreases $k_{\mathrm{ET}}$ (e.g. $3.1 \mathrm{~nm}^{2}$ per molecule, $k_{\mathrm{ET}}$ of $1.7 \times$ $10^{5} \mathrm{~s}^{-1}$ ). The authors suggest that the electron transfer between Fc units (hopping) and from Fc units to the electrode surface (heterogeneous electron transfer) is fast when the molecules are isolated. In the presence of neighboring molecules, however, intermolecular interactions restrict the motion towards the crowded electrode surfaces which decreases the $k_{\mathrm{ET}}$ values.

Ulfkjær et al. described a metal-containing [2] rotaxane, which is stoppered with gold nanoparticles (Fig. 11). ${ }^{22} \mathrm{~A}$ diammonium thread with a central Fc unit and cucurbit[7]uril self-assemble into the very stable $\left(K_{\mathrm{a}}=10^{13} \mathrm{M}^{-1}\right)$ pseudo[2] rotaxane $\mathbf{1 1}^{2+}$ in water. Basic hydrolysis gives $\mathbf{1 2}^{2+}$, whose thiol groups are able to coordinate onto gold nanoparticles to form a mechanically interlocked assembly. CV experiments were performed with the pseudo[2] rotaxanes $\mathbf{1 1}^{2+}$ and $\mathbf{1 2}^{\mathbf{2 +}}$ indicating typical anodic shifts of the $\mathrm{Fc} / \mathrm{Fc}^{+}$transition after encapsulation by cucurbit[7] uril ( $\Delta E_{1 / 2}=+0.17$ and $+0.19 \mathrm{~V}$, respectively). Scanrate-depended measurements reveal a diffusion-controlled electrochemical process for $\mathbf{1 1}^{\mathbf{2 +}}$. Normally, a diffusion coefficient smaller than that of the free thread would be expected as an indication of the increased bulkiness of the assembly. However, dithiol $\mathbf{1 2}^{\mathbf{2 +}}$ displays an abnormal diffusion coefficient 

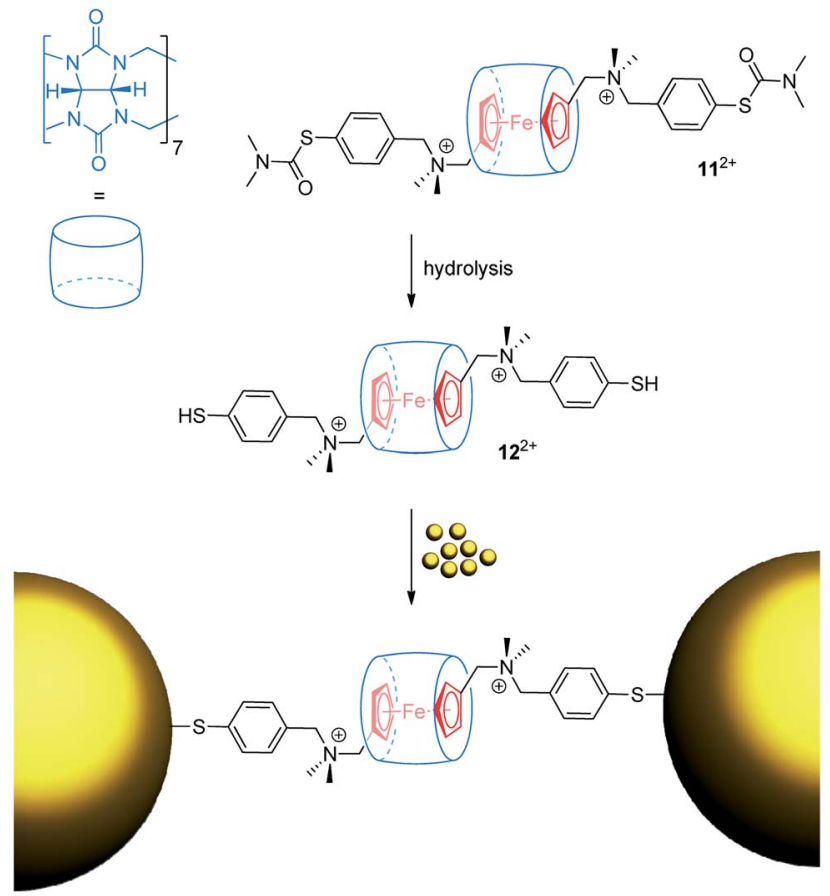

Fig. 11 Reaction scheme for the formation of a gold nanoparticlestoppered rotaxane from the pseudo[2]rotaxane precursor $12^{2+}$.

and interfacial electron transfer rate constant. The authors suggest that thiol groups bind more strongly to the surface of the used glassy carbon electrode than thiocarbamate groups; thus, pseudorotaxane $\mathbf{1 2}^{\mathbf{2 +}}$ displays interfacial rather than diffusion-controlled electron transfer kinetics.

Osakada and co-workers described a series of electro-active, Fc-containing [1-4]rotaxanes that were prepared from a common crown ether/ammonium pseudo[2]rotaxane precursor by copper-catalyzed azide-alkyne cycloaddition. ${ }^{68}$ The triazole groups of the redox-switchable [3] rotaxane can be additionally used for metal complexation. The [3]rotaxane forms $1: 1$ or $1: 2$ coordination complexes depending on the concentration of added $\mathrm{Pd}^{\mathrm{II}}$ ions.

An interesting approach of stabilizing sensitive metal complexes by rotaxanation was lately reported by the group of Terao. ${ }^{69}$ They used an $\alpha$-cyclodextrin-based [1]rotaxane as insulating shell to stabilize a $\mathrm{Ni}^{\mathrm{II}}$-bis(dithiobenzoate) complex. $\mathrm{CV}$ demonstrates a reversible and quasi-reversible reduction at -1.26 and $-1.83 \mathrm{~V} v s . \mathrm{Fc} / \mathrm{Fc}^{+}$. This represents the first example of reversible bis(dithiobenzoate) transition metal complex reduction. The same strategy was later used to stabilize a redoxactive $\mathrm{Pt}(\mathrm{II})$ bis(dithiobenzoate) complex. ${ }^{70}$

\section{Rotaxanes as ligands for metal-coordination}

Rotaxanes can provide unique coordination sites for metal ions. Goldup, Roessler and co-workers have described a library of heteroleptic metal/rotaxane complexes (Fig. 12). ${ }^{71}$ An active template synthesis followed by addition of a transition metal salt yields the heteroleptic metal/rotaxane complexes 13-15. CV and EPR reveal a reversible, metal-centered oxidation $\left(\mathrm{Cu}^{\mathrm{I} / \mathrm{II}}\right)$ at
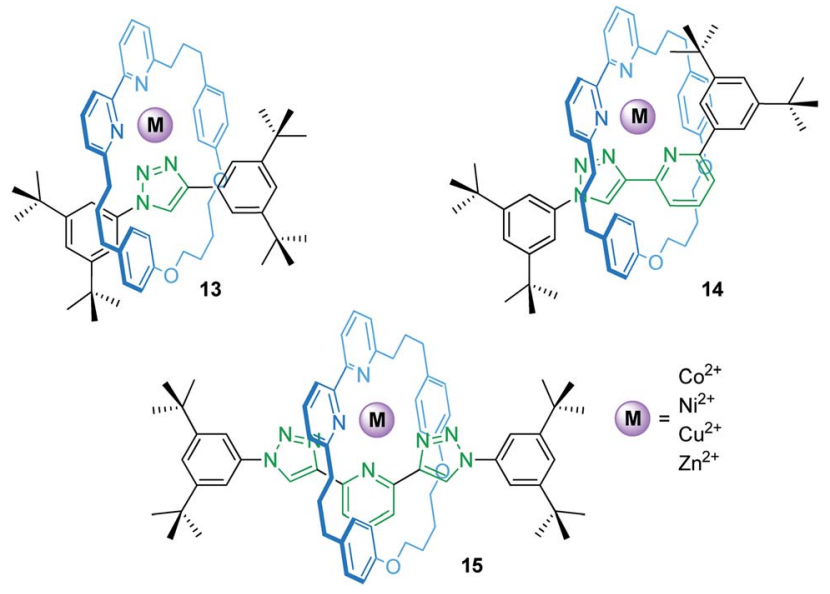

Fig. 12 Heteroleptic transition metal/rotaxane complexes 13-15 by Goldup, Roessler and co-workers.

$+0.96 \mathrm{~V}$ and $+0.56 \mathrm{~V} v s$. SHE (standard hydrogen electrode) and a reversible ligand-centered reduction at -1.50 and $-1.44 \mathrm{~V}$ for the copper species $\mathrm{Cu}(\mathbf{1 4})$ and $\mathrm{Cu}(\mathbf{1 5})$, respectively. The potential difference for the $\mathrm{Cu}^{\mathrm{I} / \mathrm{II}}$ oxidation $\left(\Delta E_{1 / 2}=0.40 \mathrm{~V}\right)$ results from the fact that $\mathbf{1 4}$ provides an ideal binding site for $\mathrm{Cu}^{\mathrm{I}}$, whereas 15 provides a flexible enough coordination sphere to sufficiently stabilize $\mathrm{Cu}^{\mathrm{I}}$ and $\mathrm{Cu}^{\mathrm{II}}$. For $\mathrm{Cu}(\mathbf{1 3})$, only an irreversible process is observed suggesting unstable $\mathrm{Cu}^{\mathrm{I}}$ and $\mathrm{Cu}^{\mathrm{II}}$ complexes. CV control experiments with a non-interlocked complex display two semi-reversible steps for the $\mathrm{Cu}^{\mathrm{I} / \mathrm{II}}$ transition caused by ligand disproportionation. Thus, the mechanical bond in 14 and 15 prevents a structural reorganization and allows redox-reactions without degradation of the complexes which would otherwise not be achievable.

The groups of Armaroli and Diederich synthesized a $\mathrm{Cu}^{\mathrm{I}}$ bisphenanthroline rotaxane by using tetracyano- $p$-quinodimethane as the stopper unit in a $[2+2]$ cycloaddition-retroelectrocyclization. ${ }^{72}$ Electrochemical experiments revealed for the resulting rotaxane a reversible $\mathrm{Cu}^{\mathrm{I} / \mathrm{II}}$ oxidation and two reversible one-electron reductions for the dicyanoquinodimethane moiety, which was generated during the stoppering reaction.

An efficient operation of multi-ring rotaxanes, such as in the case of palindromic [3]rotaxanes, requires an ingenious design of a switchable supramolecular binding motif. The group of Flood developed a novel construction motif for $\mathrm{Cu}^{\mathrm{I}}$-containing pseudo[3]rotaxane (Fig. 13). ${ }^{73}$ Their multi-component system consists of a phenanthroline-bearing macrocycle, $\mathrm{Cu}^{\mathrm{I}}$ ions, a 5,5'-dimethyl-2,2'-bipyridine ligand, and a redox-switchable 3,6-bis(5'-methyl-2-pyridyl)-1,2,4,5-tetrazine ligand. In the initial state, $\mathrm{Cu}^{\mathrm{I}}$ favors coordination by one macrocycle and one bipyridine ligand. Thus, the potential for single-electron reduction of the tetrazine ligand $\left(E_{\mathrm{pc}}=-0.95 \mathrm{~V} v s\right.$. $\left.\mathrm{Ag} / \mathrm{AgCl}\right)$ is mainly unaffected. Reduction of the tetrazine to its radical anionic form, however, dramatically enhances its ligand strength and initiates ligand exchange with the bipyridines to form the pseudo[3]rotaxane $\mathbf{1 6}^{+}$. As shown by an anodically shifted re-oxidation potential $\left(E_{\mathrm{pa}}=-0.25 \mathrm{~V}\right)$, the pseudo[3] 

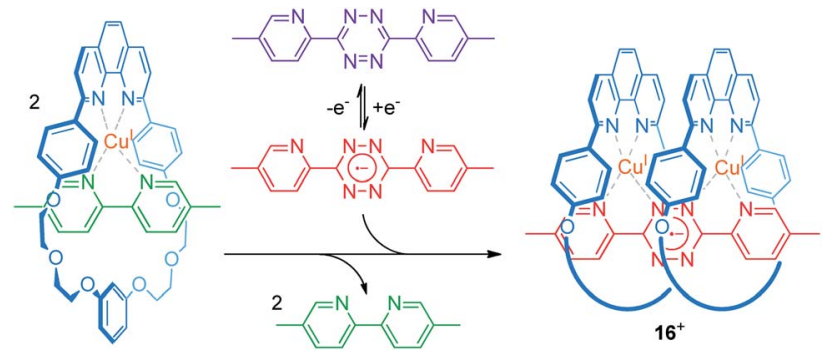

Fig. 13 Electrochemical switching of a multi-component system to reversibly form the palindromic pseudo[3]rotaxane $16^{+}$.

rotaxane state is energetically stabilized. Digital simulations and control experiments confirm a stepwise mechanism. The first step (exchange with the first bipyridine $/ \mathrm{Cu}^{\mathrm{I}} / \mathrm{macrocycle}$ complex) is significantly faster than the second step, due to increased bulkiness of the intermediate pseudo[2]rotaxane. However, the second step displays a higher thermodynamic driving force (19vs. $25 \mathrm{~kJ} \mathrm{~mol}^{-1}$ ) in accordance with a positive thermodynamic cooperativity. Flood recently reported a similar observation for non-covalently coupled "cyanostar" macrocycles in a metal-free pseudo[3]rotaxane. ${ }^{74}$

\section{Applications of redox-active rotaxanes}

Electrochemically switchable rotaxanes are obviously appealing for integration into electronic devices, for example by interfacing them with electrodes. ${ }^{75,76}$ Starting more than a decade ago, switchable rotaxanes on solid supports have been intensively studied in self-assembled monolayers. ${ }^{77-81}$ This research greatly expanded the fundamental understanding of molecular switching on solid support, but also disclosed that organic structures often suffer from low long-term persistence and structural integrity. ${ }^{82,83}$ However, in recent years also other applications arose from access to novel construction motifs for redox-active rotaxanes.

Beer developed a halogen bonding [2] rotaxane $^{84}$ which can serve as an electrochemical bromide sensor, even in watercontaining media (Fig. 14). Rotaxane $\mathbf{1 7}^{+}$provides a halogenbonding anion binding cavity and a ferrocene unit as an electrochemical probe. ${ }^{1} \mathrm{H}$ NMR titration experiments in an organic solvent mixture with 10 vol $\% \mathrm{D}_{2} \mathrm{O}$ give association constants for the anions $\mathrm{Cl}^{-}, \mathrm{Br}^{-}, \mathrm{I}^{-}$and $\mathrm{SCN}^{-}$, which the authors report to be $101,340,1125$ and $102 \mathrm{M}^{-1}$, respectively. The halide anions nicely follow the Hofmeister series; however, the $\mathrm{SCN}^{-}$anion, which should exceed $\mathrm{I}^{-}$, displays a rather poor binding indicating that geometry and size complementarity play a crucial role. The electrochemical response to $\mathrm{Cl}^{-}, \mathrm{Br}^{-}$and $\mathrm{SCN}^{-}$was further probed by square-wave voltammetry showing cathodic shifts for the $\mathrm{Fc} / \mathrm{Fc}^{+}$transition. Whereas addition of 20 equivalents of $\mathrm{Cl}^{-}$and $\mathrm{SCN}^{-}$display negligibly small shifts $\left(\Delta E_{1 / 2}<5\right.$ $\mathrm{mV}$ ), the addition of $\mathrm{Br}^{-}$generates more pronounced shifts (e.g. 20 equiv. result in $\Delta E_{1 / 2}=-10 \mathrm{mV}$ ). Control experiments in dry and "wet" solvents indicate that hydration strongly contributes to the observed effects. This is in line with the more pronounced voltammetric response for $\mathrm{Br}^{-}$, since $\mathrm{Br}^{-}$is expected to display

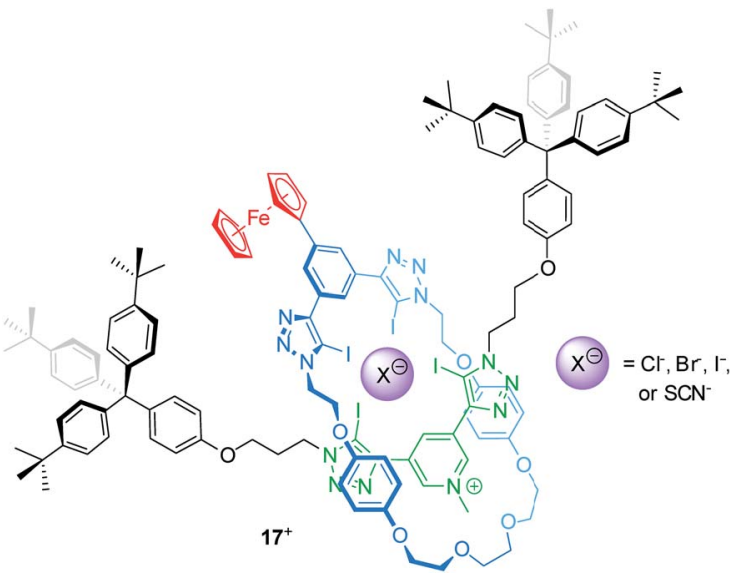

Fig. 14 Structure of the bromide-sensing [2]rotaxane $17^{+}$, which provides a halogen bonding anion binding cavity.

lower hydration energy. In another recent report, Beer presented a Fc-decorated [3]rotaxane shuttle which utilizes anion recognition to induce wheel translation..$^{85}$

The Tanaka group has described porphyrin-phthalocyanine catalyst $\mathbf{1 8}^{\mathbf{4 +}}$ for $\mathrm{O}_{2}$ to $\mathrm{H}_{2} \mathrm{O}$ reduction, ${ }^{86}$ which is based on their previously reported fourfold threaded [2]rotaxane motif ${ }^{87}$ (Fig. 15a). The heterodimeric scaffold incorporates a $\mu$-oxodinuclear iron complex $\left(\mathrm{Fe}^{\mathrm{III}}-\mathrm{O}-\mathrm{Fe}^{\mathrm{III}}\right)$. Experiments using a rotating ring disc electrode showed a fairly high positive onset potential of $0.78 \mathrm{~V}$ vs. RHE (reversible hydrogen electrode) indicating a high catalytic activity for oxygen reduction.

Furthermore, the determined number of 3.8 transferred electrons (at $0.47 \mathrm{~V}$ ) and the percentage of $\mathrm{H}_{2} \mathrm{O}$ generation (88\%) confirm that a four-electron reduction of $\mathrm{O}_{2}$ to $\mathrm{H}_{2} \mathrm{O}$ is the dominant reaction. As shown by $\mathrm{CV}$, the $E_{\mathrm{pc}}$ value of a redoxwave at $E_{1 / 2}=0.60 \mathrm{~V}$, corresponding to a one-electron reduction of the $\mathrm{Fe}^{\mathrm{III}}$ phthalocyanine complex, significantly increases in the presence of $\mathrm{O}_{2}$. The proposed mechanism, in which protonation and $\mathrm{Fe}^{\mathrm{III}}$ phthalocyanine reduction result in an initial water loss, is shown in Fig. 15b. Subsequently, the resulting mixed-valence species and $\mathrm{O}_{2}$ form a peroxo- $\mathrm{Fe}^{\mathrm{III}}$
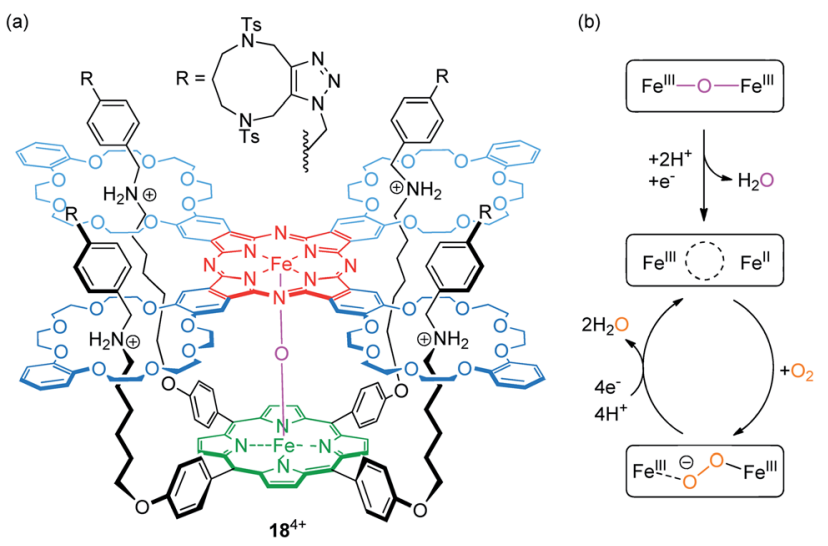

Fig. 15 (a) Structure of the fourfold threaded [2] rotaxane catalyst $18^{4+}$, which incorporates a $\mu$-oxo-dinuclear iron complex. (b) Suggested mechanism for the reduction of oxygen to water. 
complex $\left(\mathrm{Fe}^{\mathrm{III}} \cdots \mathrm{O}^{-}-\mathrm{O}-\mathrm{Fe}^{\mathrm{III}}\right)$, which releases, after four-electron reduction and protonation, two $\mathrm{H}_{2} \mathrm{O}$ molecules. The authors attribute the high catalytic activity to the flexible rotaxane scaffold and its inherent structural adaptability. It provides a well suitable environment to accommodate the longer $\mathrm{O}_{2}$ molecule as well as the shorter bridging $\mathrm{O}^{2-}$ ligand.

Conjugated molecular chains that conduct electric current-so-called molecular wires-are attracting considerable attention due to their potential use for nanoscale electronic devices. Fig. 16 shows rotaxane 19, consisting of an oligoyne thread with 6 conjugated triple bonds, which is assembled within a scanning tunneling microscope break junction. ${ }^{88}$ Both, the presence of the 3,5-diphenylpyridine endcapping groups and the encircled phenanthroline containing macrocycle, chemically stabilize the oligoyne by steric shielding and yield a kind of insulated molecular wire. Molecular conductance measurements showed a slight increase of conductance for the rotaxane $\mathbf{1 9}$ compared to the free thread suggesting a rather small effect of the wheel on the electronic structure of the thread. Rotaxanation also comes with a drawback: due to the possibility of inhibiting molecular bridging between wheel and gold contacts, the presence of the threaded wheel reduces the probability for successful molecular junction formation.

A series of heteroleptic $\mathrm{Cu}^{\mathrm{I}}$ pseudo[2]rotaxanes featuring bis[2(diphenylphosphino)phenyl] ether and macrocyclic phenanthroline ligands have been recently investigated as materials for organic light emitting diodes (OLEDs). ${ }^{89}$ In a poly(methyl methacrylate) film (1 wt\%), they exhibit excellent photophysical properties with photoluminescence quantum yields up to $44 \%\left(\lambda_{\text {exc }}=\right.$ $380 \mathrm{~nm}$ ), which makes them promising for optoelectronic devices. An OLED device based on one of the $\mathrm{Cu}^{\mathrm{I}}$ pseudorotaxanes shows intense green electroluminescence at $10 \mathrm{~V}$ with a maximum intensity at $\sim 520 \mathrm{~nm}$. It is noteworthy that the pseudorotaxane displays a higher electroluminescence and enhanced device stability compared to a reference compound with a nonmacrocyclic phenanthroline ligand. The authors attribute the improved performance to the pseudorotaxane structure that prevents complex disassembly and, thus, chemical degradation.

Transport and controlled release of substrates are vital functions of natural molecular machines. Credi and coworkers have reported a synthetic molecular transporter based on the [2]rotaxane $\mathbf{2 0}^{\mathbf{5}^{+}}$(Fig. 17). ${ }^{\mathbf{9}}$ The crown ether

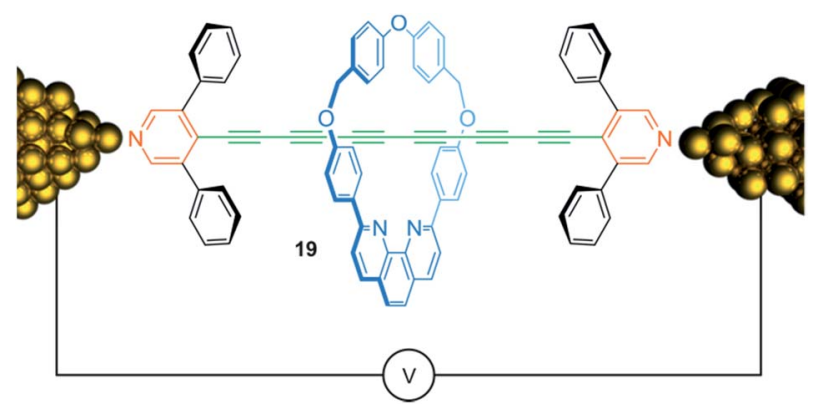

Fig. 16 Schematic representation of oligoyne rotaxane 19 within in a single molecule break junction.

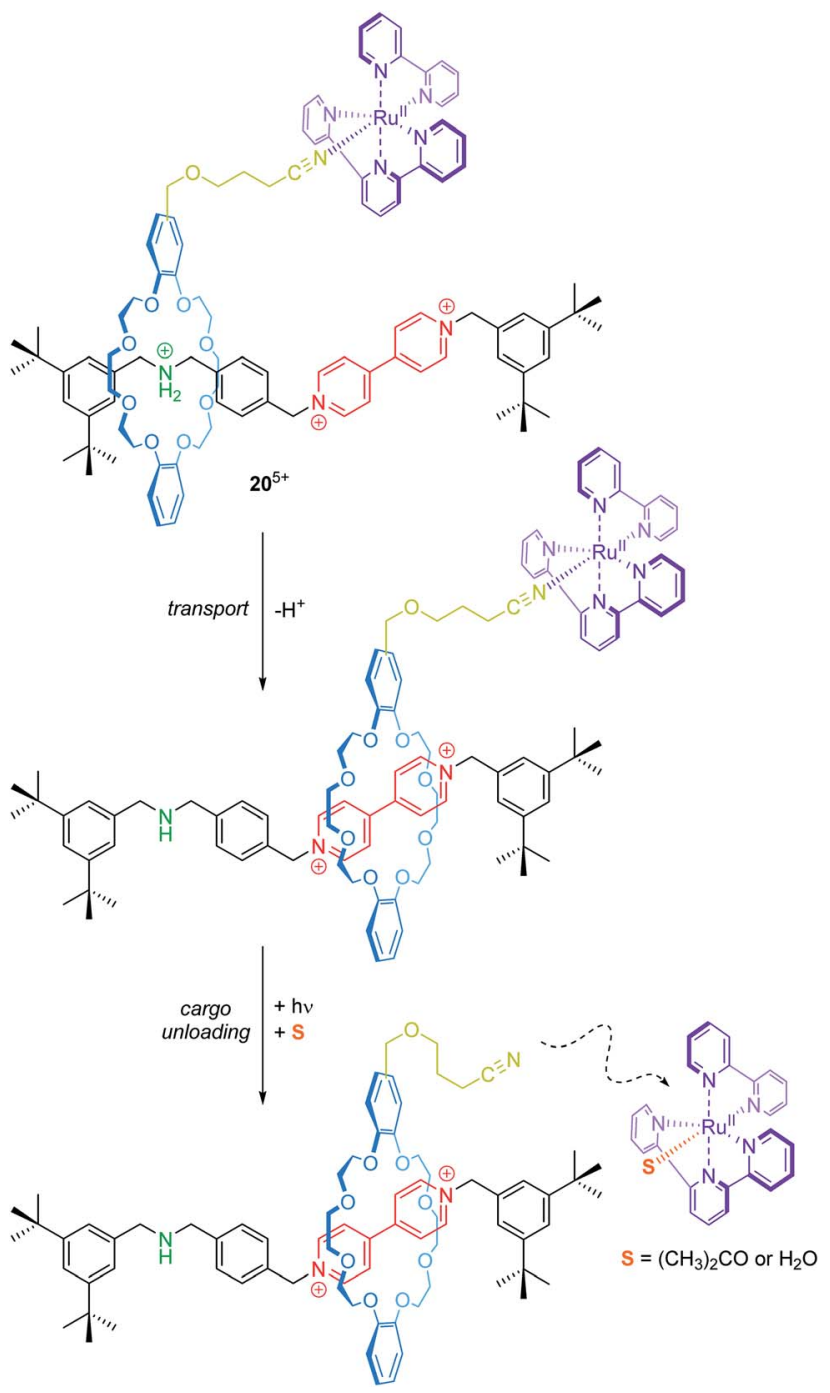

Fig. 17 Operation sequence of rotaxane-based molecular transporter $20^{5+}$ by orthogonal use of acid/base addition and light as external stimuli. The dashed arrow illustrates the release of the formerly bound Ru" complex.

wheel of the rotaxane carries a ruthenium complex, which acts as a molecular cargo. The position of the $\mathrm{Ru}^{\mathrm{II}}$ complex on the thread can be manipulated by acid/base addition. Irradiation with visible light triggers a ligand exchange and the $\mathrm{Ru}^{\mathrm{II}}$ complex dissociates from the rotaxane (unloading). Here, electrochemistry serves as a tool to monitor in situ operation of the transporter. In the protonated state, two one-electron reduction processes for the bipyridinium unit at -0.35 and $-0.75 \mathrm{~V} v s$. SCE and a metal-centered oxidation at $+1.34 \mathrm{~V}$ are observed. Deprotonation leads to wheel shuttling (transport) towards the viologen station and cathodically shifts both reduction potentials of it, whereas the $\mathrm{Ru}^{\mathrm{II} / \mathrm{III}}$ oxidation remains unaffected. After irradiation, however, the signal at $+1.34 \mathrm{~V}$ disappears indicating a successful photodissociation. Although the transport distance is rather small, this proof-ofprinciple nicely illustrates that artificial systems are capable of reversibly performing transport and cargo loading/unloading processes. 


\section{Non-equilibrium systems}

A fundamental difference between synthetic molecular switches and nature's molecular machines, such as motor proteins, is that the former are found in states of thermodynamic equilibrium whereas the latter are dissipative systems operating far from it. ${ }^{91}$ Switching as described so far brings the system out of equilibrium, when the stimulus is applied, but the system reacts into a new equilibrium situation, for example by wheel shuttling along the axle.

The construction of true non-equilibrium systems, which generate directed molecular motion by consuming energy or fuel, is therefore the next logical step towards autonomously operating artificial molecular machinery. ${ }^{92}$ Recently, the Leigh group has reported on chemically fueled catenane motors ${ }^{\mathbf{9 3 , 9 4}}$ which generate unidirectional rotary motion. Credi and others described a pseudorotaxane-based molecular pump, ${ }^{95}$ in which a ring is directionally transported under irradiation of light. Furthermore, the groups of Browne ${ }^{96}$ and Feringa ${ }^{97}$ have examined the control of unidirectional rotation in molecular motors by redox-chemistry.

In a series of recent papers, the Stoddart group developed variants of electrochemically driven molecular pumps which operate in non-equilibrium states. ${ }^{\mathbf{9 8 - 1 0 0}}$ Through an elegantly designed sequence of steric "speed bumps" and redoxswitchable binding sites implemented into a molecular axle, macrocycles can be transported along the thread. An energy ratchet mechanism driven by redox oscillations enables a directional transport. If the axle is stoppered at the output side, it is even possible to accumulate multiple wheels on the axle.

Fig. 18 shows the operation sequence of their latest system, ${ }^{\mathbf{1 0 0}}$ which involves the symmetric axle $21^{\mathbf{8 +}}$ consisting of two molecular pumping units at its ends and a central reservoir to accumulate $\mathrm{CBPQT}^{4+}$ wheels. In the ground state, the tetra-cationic wheel and the 3,5-dimethylpyridinium/ viologen moiety repel each other (state I). Upon reduction, however, repulsion is reduced and a $\mathrm{CBPQT}^{2(\cdot+)}$ ring from the bulk solution threads on the axle to form a tri-radical complex with the radical cationic viologen unit (state II). Re-oxidation of the ensemble destabilizes the complex and drives the wheel over the steric barrier given by the isopropylphenyl moiety. The wheel slips into the reservoir domain where it is kinetically trapped (state III). After one redox cycle, it is possible to repeat the process and collect another wheel on each half of the symmetric thread to yield a [5]rotaxane (state IV). Consecutive chemical reduction/oxidation is experimentally difficult due to formation of waste products. ${ }^{\mathbf{1 0 0}}$ However, the ratchet mechanism can also be powered by bulk electrolysis cycles in which the working electrode is alternately held at a constant reductive or oxidative potential. (a)

state

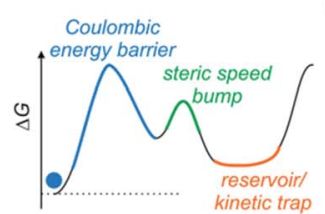

$\downarrow$

state

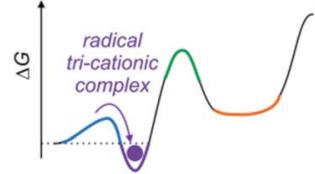

$\downarrow$
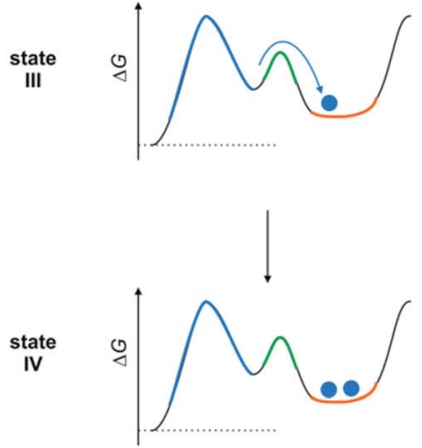

(b)

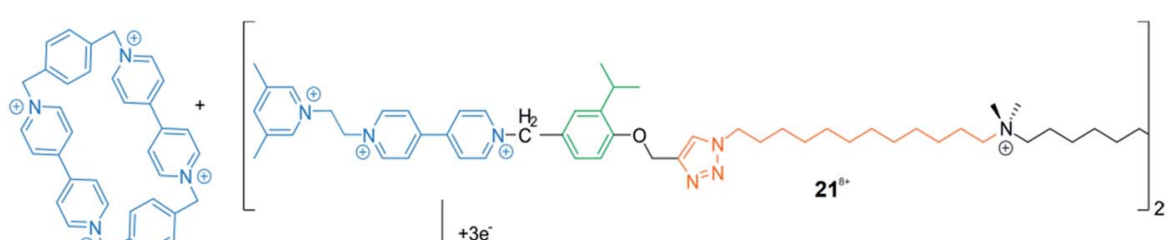

$+3 \mathrm{e}^{-}$ $\checkmark$
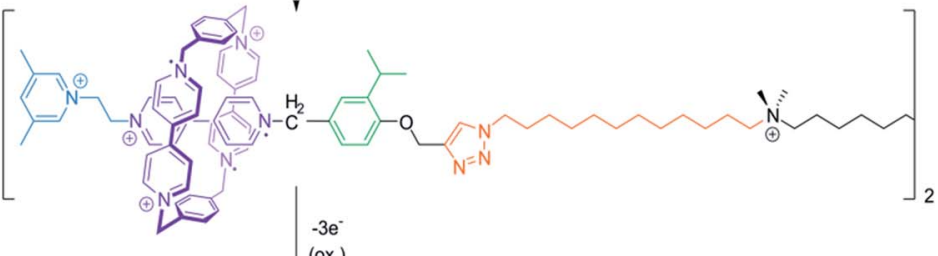

(ox.)

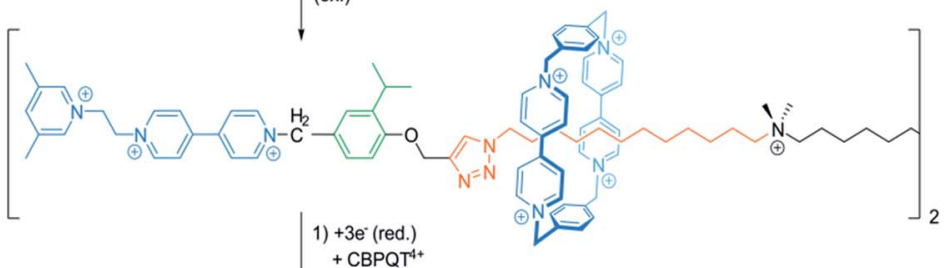

2) $-3 e^{-}(0 x$.

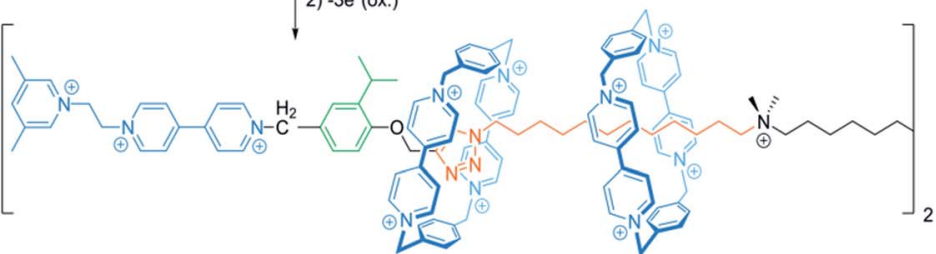

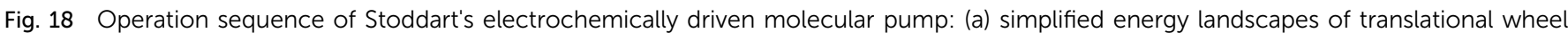

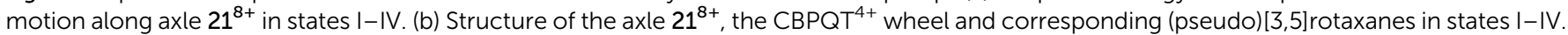




\section{Conclusions and perspectives}

In their 1994 Nature publication ${ }^{27}$ on the first electrochemically switchable molecular shuttle, the authors concluded with an appeal to the community of supramolecular chemists: “(...) to improve the molecular properties of these and related systems (...)". Based on tremendous progress in synthesizing mechanically interlocked molecules, the last 25 years have witnessed this improvement accompanied by an ongoing diversification of rotaxanes towards more complex and functional systems. As shown in this perspective, electrochemically switchable rotaxanes come in a large variety of structure and properties nowadays. The field continues to develop quickly.

However, the ongoing growth of complexity of supramolecular architectures also comes with the necessity of improved strategies for subcomponent self-assembly. Advanced synthetic strategies like dynamic combinatorial chemistry or self-sorting will play a pivotal role in the construction of future systems. For example, it has been demonstrated that large, redox-active oligorotaxanes can be efficiently constructed by using dynamic covalent chemistry. ${ }^{\mathbf{1 0 1}}$

Furthermore, few supramolecular construction motifs have proven to be particularly reliable for introducing electrochemical switching into rotaxanes, e.g. viologens ${ }^{\mathbf{1 0 2}}$ and tetrathiafulvalenes, ${ }^{103}$ which provide stable and persistent redoxswitchable building blocks. The improvement of these functional groups and the development of novel yet functionally similar redox-switches are of major significance for future growth of the field.

What to expect in the future of electrochemically switchable rotaxanes? Regarding electroanalytical methods, it is assumed that optoelectronic properties of switchable molecules will increasingly be probed through single-molecule experiments ${ }^{\mathbf{1 0 4}}$ and combined spectroelectrochemical methods, ${ }^{\mathbf{1 0 5}}$ which complement and expand classical bulk and interfacial techniques.

Due to the limited long-term stability of organic molecules in solution and on surfaces, a widespread application of rotaxanes, e.g. in hybrid electronic devices, comes with difficulties. However, recent developments in metal-organic rotaxanes or the stabilization of switchable rotaxanes in metal-organic frameworks ${ }^{83}$ open new pathways towards persistent systems. The use of rotaxanes as unique ligands for metal coordination also comes along with it. Regarding artificial molecular machines, electrochemical energy has already been shown to be an excellent choice to effectively fuel directional molecular motions; thus, we may expect that new generations of redoxdriven molecular machines and motors will appear soon. Non-equilibrium self-assembly will also strongly contribute to the future of molecular machines and some upcoming examples of dissipative systems could perhaps surpass their role models from nature in some aspects.

\section{Conflicts of interest}

There are no conflicts to declare.

\section{Acknowledgements}

We thank the Deutsche Forschungsgemeinschaft (CRC 765) for financial support. We are also grateful to Chih-Wei Chu, Marius Gaedke and Claudia Kästner for helpful discussions.

\section{Notes and references}

1 M. Xue, Y. Yang, X. Chi, X. Yan and F. Huang, Chem. Rev., 2015, 115, 7398-7501.

2 J. D. Crowley, S. M. Goldup, A. L. Lee, D. A. Leigh and R. T. McBurney, Chem. Soc. Rev., 2009, 38, 1530-1541.

3 C. A. Schalley, F. Vögtle and K. H. Dötz, Templates in Chemistry I, Springer, Heidelberg, Germany, 2004.

4 R. Jäger and F. Vögtle, Angew. Chem., Int. Ed. Engl., 1997, 36, 930-944.

5 M. M. Safont-Sempere, G. Fernandez and F. Würthner, Chem. Rev., 2011, 111, 5784-5814.

6 Z. He, W. Jiang and C. A. Schalley, Chem. Soc. Rev., 2015, 44, 779-789.

7 P. T. Corbett, J. Leclaire, L. Vial, K. R. West, J. L. Wietor, J. K. Sanders and S. Otto, Chem. Rev., 2006, 106, 3652-3711.

8 J. M. Lehn, Chem. Soc. Rev., 2007, 36, 151-160.

9 F. B. Cougnon and J. K. Sanders, Acc. Chem. Res., 2012, 45, 2211-2221.

10 R. S. Forgan, J. P. Sauvage and J. F. Stoddart, Chem. Rev., 2011, 111, 5434-5464.

11 O. Lukin, A. Godt and F. Vögtle, Chem.-Eur. J., 2004, 10, 1878-1883.

12 D. Sluysmans and J. F. Stoddart, Trends in Chemistry, 2019, 1, 185-197.

13 C. J. Bruns and J. F. Stoddart, The Nature of the Mechanical Bond: From Molecules to Machines, Wiley, Hoboken, New Jersey, USA, 2016.

14 S. Erbas-Cakmak, D. A. Leigh, C. T. McTernan and A. L. Nussbaumer, Chem. Rev., 2015, 115, 10081-10206.

15 W. R. Browne and B. L. Feringa, Nat. Nanotechnol., 2006, 1, 25-35.

16 V. Balzani, A. Credi, F. M. Raymo and J. F. Stoddart, Angew. Chem., Int. Ed., 2000, 39, 3348-3391.

17 H. R. Tseng, S. A. Vignon and J. F. Stoddart, Angew. Chem., Int. Ed., 2003, 42, 1491-1495.

18 A. Credi, M. Semeraro, S. Silvi and M. Venturi, Antioxid. Redox Signaling, 2011, 14, 1119-1165.

19 C. Sandford, M. A. Edwards, K. J. Klunder, D. P. Hickey, M. Li, K. Barman, M. S. Sigman, H. S. White and S. D. Minteer, Chem. Sci., 2019, 10, 6404-6422.

20 M. Franz, J. A. Januszewski, D. Wendinger, C. Neiss, L. D. Movsisyan, F. Hampel, H. L. Anderson, A. Gorling and R. R. Tykwinski, Angew. Chem., Int. Ed., 2015, 54, 6645-6649.

21 J. Heinze, Angew. Chem., Int. Ed. Engl., 1984, 23, 831-847.

22 A. Ulfkjær, F. W. Nielsen, H. Al-Kerdi, T. Rubeta, Z. K. Nielsen, J. Ulstrup, L. Sun, K. Moth-Poulsen, J. Zhang and M. Pittelkow, Nanoscale, 2018, 10, 9133-9140.

23 H. V. Schröder, H. Hupatz, A. J. Achazi, S. Sobottka, B. Sarkar, B. Paulus and C. A. Schalley, Chem.-Eur. J., 2017, 23, 2960-2967. 
24 A. E. Kaifer and M. Gómez-Kaifer, Supramolecular Electrochemistry, Wiley, Weinheim, Germany, 1999.

25 C. A. Schalley, Analytical Methods in Supramolecular Chemistry, Wiley, Weinheim, Germany, 2012.

26 G. Ragazzon, A. Credi and B. Colasson, Chem.-Eur. J., 2017, 23, 2149-2156.

27 R. A. Bissell, E. Córdova, A. E. Kaifer and J. F. Stoddart, Nature, 1994, 369, 133-137.

28 B. L. Feringa, Angew. Chem., Int. Ed., 2017, 56, 11060-11078. 29 J. F. Stoddart, Angew. Chem., Int. Ed., 2017, 56, 11094-11125. 30 J. P. Sauvage, Angew. Chem., Int. Ed., 2017, 56, 11080-11093. 31 H. Tian and Q. C. Wang, Chem. Soc. Rev., 2006, 35, 361-374. 32 S. F. van Dongen, S. Cantekin, J. A. Elemans, A. E. Rowan and R. J. Nolte, Chem. Soc. Rev., 2014, 43, 99-122.

33 J.-P. Sauvage, Acc. Chem. Res., 1998, 31, 611-619.

34 J. E. M. Lewis, P. D. Beer, S. J. Loeb and S. M. Goldup, Chem. Soc. Rev., 2017, 46, 2577-2591.

35 P. Ceroni, A. Credi and M. Venturi, Electrochemistry of Functional Supramolecular Systems, Wiley, Hoboken, New Jersey, USA, 2010.

36 C. A. Nijhuis, B. J. Ravoo, J. Huskens and D. N. Reinhoudt, Coord. Chem. Rev., 2007, 251, 1761-1780.

37 A. C. Fahrenbach, C. J. Bruns, D. Cao and J. F. Stoddart, Acc. Chem. Res., 2012, 45, 1581-1592.

38 A. C. Fahrenbach, C. J. Bruns, H. Li, A. Trabolsi, A. Coskun and J. F. Stoddart, Acc. Chem. Res., 2014, 47, 482-493.

39 D. Britz and J. Strutwolf, Digital Simulation in Electrochemistry, Springer, Basel, Switzerland, 2016.

40 A. Altieri, F. G. Gatti, E. R. Kay, D. A. Leigh, D. Martel, F. Paolucci, A. M. Slawin and J. K. Wong, J. Am. Chem. Soc., 2003, 125, 8644-8654.

41 M. R. Panman, C. N. van Dijk, A. Huerta-Viga, H. J. Sanders, B. H. Bakker, D. A. Leigh, A. M. Brouwer, W. J. Buma and S. Woutersen, Nat. Commun., 2017, 8, 2206.

42 D. A. Leigh, P. J. Lusby, A. M. Z. Slawin and D. B. Walker, Angew. Chem., Int. Ed., 2005, 117, 4633-4640.

43 Y. Wang, T. Cheng, J. Sun, Z. Liu, M. Frasconi, W. A. Goddard III and J. F. Stoddart, J. Am. Chem. Soc., 2018, 140, 13827-13834.

44 M. D. Kilde, R. Kristensen, G. Olsen, J. O. Jeppesen and M. B. Nielsen, Eur. J. Org. Chem., 2019, 5532-5539.

45 H. V. Schröder, S. Sobottka, M. Nössler, H. Hupatz, M. Gaedke, B. Sarkar and C. A. Schalley, Chem. Sci., 2017, 8, 6300-6306.

46 C. J. Bruns and J. F. Stoddart, Acc. Chem. Res., 2014, 47, 2186-2199.

47 Y. Liu, A. H. Flood, P. A. Bonvallet, S. A. Vignon, B. H. Northrop, H. R. Tseng, J. O. Jeppesen, T. J. Huang, B. Brough, M. Baller, S. Magonov, S. D. Solares, W. A. Goddard III, C. M. Ho and J. F. Stoddart, J. Am. Chem. Soc., 2005, 127, 9745-9759.

48 Y. Wang, M. Frasconi, W. G. Liu, J. Sun, Y. Wu, M. S. Nassar, Y. Y. Botros, W. A. Goddard III, M. R. Wasielewski and J. F. Stoddart, ACS Cent. Sci., 2016, 2, 89-98.

49 H. V. Schröder, F. Stein, J. M. Wollschläger, S. Sobottka, M. Gaedke, B. Sarkar and C. A. Schalley, Angew. Chem., Int. Ed., 2019, 58, 3496-3500.
50 A. Wolf, J. J. Cid, E. Moulin, F. Niess, G. Y. Du, A. Goujon, E. Busseron, A. Ruff, S. Ludwigs and N. Giuseppone, Eur. J. Org. Chem., 2019, 3421-3432.

51 Y. Takashima, K. Otani, Y. Kobayashi, H. Aramoto, M. Nakahata, H. Yamaguchi and A. Harada, Macromolecules, 2018, 51, 6318-6326.

52 E. R. Janecek, J. R. McKee, C. S. Tan, A. Nykanen, M. Kettunen, J. Laine, O. Ikkala and O. A. Scherman, Angew. Chem., Int. Ed., 2015, 54, 5383-5388.

53 Q. Zhang, D. H. Qu, Q. C. Wang and H. Tian, Angew. Chem., Int. Ed., 2015, 54, 15789-15793.

54 Y. Ahn, Y. Jang, N. Selvapalam, G. Yun and K. Kim, Angew. Chem., Int. Ed., 2013, 52, 3140-3144.

55 Y. Wang, J. Sun, Z. Liu, M. S. Nassar, Y. Y. Botros and J. F. Stoddart, Chem. Sci., 2017, 8, 2562-2568.

56 H. V. Schröder, J. M. Wollschläger and C. A. Schalley, Chem. Commun., 2017, 53, 9218-9221.

57 M. R. Panman, B. H. Bakker, D. den Uyl, E. R. Kay, D. A. Leigh, W. J. Buma, A. M. Brouwer, J. A. Geenevasen and S. Woutersen, Nat. Chem., 2013, 5, 929-934.

58 P. Farras, E. C. Escudero-Adan, C. Vinas and F. Teixidor, Inorg. Chem., 2014, 53, 8654-8661.

59 H. V. Schröder, A. Mekic, H. Hupatz, S. Sobottka, F. Witte, L. H. Urner, M. Gaedke, K. Pagel, B. Sarkar, B. Paulus and C. A. Schalley, Nanoscale, 2018, 10, 21425-21433.

60 S. S. Andersen, A. W. Saad, R. Kristensen, T. S. Pedersen, L. J. O'Driscoll, A. H. Flood and J. O. Jeppesen, Org. Biomol. Chem., 2019, 17, 2432-2441.

61 M. C. Lipke, Y. Wu, I. Roy, Y. Wang, M. R. Wasielewski and J. F. Stoddart, ACS Cent. Sci., 2018, 4, 362-371.

62 M. C. Lipke, T. Cheng, Y. Wu, H. Arslan, H. Xiao, M. R. Wasielewski, W. A. Goddard III and J. F. Stoddart, J. Am. Chem. Soc., 2017, 139, 3986-3998.

63 C. O. Dietrich-Buchecker, J. P. Sauvage and J. P. Kintzinger, Tetrahedron Lett., 1983, 24, 5095-5098.

64 K. M. Tomczyk, M. Woźny, S. Domagała, A. Wiȩckowska, J. Pawłowska, K. Woźniak and B. Korybut-Daszkiewicz, New J. Chem., 2017, 41, 6004-6013.

65 M. Woźny, K. M. Tomczyk, A. Więckowska, S. Sutuła, D. Trzybiński, K. Woźniak and B. Korybut-Daszkiewicz, Dalton Trans., 2019, 48, 6546-6557.

66 X. Ma, J. Zhang, J. Cao, X. Yao, T. Cao, Y. Gong, C. Zhao and H. Tian, Chem. Sci., 2016, 7, 4582-4588.

67 M. Steffenhagen, A. Latus, T. M. N. Trinh, I. Nierengarten, I. T. Lucas, S. Joiret, J. Landoulsi, B. Delavaux-Nicot, J. F. Nierengarten and E. Maisonhaute, Chem.-Eur. J., 2018, 24, 1701-1708.

68 G. Yu, Y. Suzaki and K. Osakada, RSC Adv., 2016, 6, 4136941375.

69 T. Hosomi, R. Harada, H. Masai, T. Fujihara, Y. Tsuji and J. Terao, Chem. Commun., 2018, 54, 2487-2490.

70 R. Harada, T. Hosomi, H. Masai and J. Terao, Tetrahedron Lett., 2018, 59, 2930-2933.

71 M. Cirulli, A. Kaur, J. E. M. Lewis, Z. Zhang, J. A. Kitchen, S. M. Goldup and M. M. Roessler, J. Am. Chem. Soc., 2019, 141, 879-889. 
72 Y. Trolez, A. D. Finke, F. Silvestri, F. Monti, B. Ventura, C. Boudon, J. P. Gisselbrecht, W. B. Schweizer, J. P. Sauvage, N. Armaroli and F. Diederich, Chem.-Eur. J., 2018, 24, 10422-10433.

73 C. R. Benson, A. I. Share, M. G. Marzo and A. H. Flood, Inorg. Chem., 2016, 55, 3767-3776.

74 C. R. Benson, C. Maffeo, E. M. Fatila, Y. Liu, E. G. Sheetz, A. Aksimentiev, A. Singharoy and A. H. Flood, Proc. Natl. Acad. Sci. U. S. A., 2018, 115, 9391-9396.

75 A. Ulman, Chem. Rev., 1996, 96, 1533-1554.

76 A. C. Fahrenbach, S. C. Warren, J. T. Incorvati, A. J. Avestro, J. C. Barnes, J. F. Stoddart and B. A. Grzybowski, Adv. Mater., 2013, 25, 331-348.

77 Y. Luo, C. P. Collier, J. O. Jeppesen, K. A. Nielsen, E. DeIonno, G. Ho, J. Perkins, H.-R. Tseng, T. Yamamoto, J. F. Stoddart and J. R. Heath, ChemPhysChem, 2002, 3, 519-525.

78 J. R. Heath and M. A. Ratner, Phys. Today, 2003, 56, 43-49. 79 J. E. Green, J. W. Choi, A. Boukai, Y. Bunimovich, E. Johnston-Halperin, E. DeIonno, Y. Luo, B. A. Sheriff, K. Xu, Y. S. Shin, H. R. Tseng, J. F. Stoddart and J. R. Heath, Nature, 2007, 445, 414-417.

80 T. J. Huang, B. Brough, C.-M. Ho, Y. Liu, A. H. Flood, P. A. Bonvallet, H.-R. Tseng, J. F. Stoddart, M. Baller and S. Magonov, Appl. Phys. Lett., 2004, 85, 5391-5393.

81 E. Katz, O. Lioubashevsky and I. Willner, J. Am. Chem. Soc., 2004, 126, 15520-15532.

82 A. Coskun, J. M. Spruell, G. Barin, W. R. Dichtel, A. H. Flood, Y. Y. Botros and J. F. Stoddart, Chem. Soc. Rev., 2012, 41, 4827-4859.

83 P. R. McGonigal, P. Deria, I. Hod, P. Z. Moghadam, A. J. Avestro, N. E. Horwitz, I. C. Gibbs-Hall, A. K. Blackburn, D. Chen, Y. Y. Botros, M. R. Wasielewski, R. Q. Snurr, J. T. Hupp, O. K. Farha and J. F. Stoddart, Proc. Natl. Acad. Sci. U. S. A., 2015, 112, 11161-11168.

84 J. Y. C. Lim and P. D. Beer, Eur. J. Org. Chem., 2019, 2019, 3433-3441.

85 T. A. Barendt, I. Rasovic, M. A. Lebedeva, G. A. Farrow, A. Auty, D. Chekulaev, I. V. Sazanovich, J. A. Weinstein, K. Porfyrakis and P. D. Beer, J. Am. Chem. Soc., 2018, 140, 1924-1936.

86 N. Mihara, Y. Yamada, H. Takaya, Y. Kitagawa, S. Aoyama, K. Igawa, K. Tomooka and K. Tanaka, Chem.-Eur. J., 2017, 23, 7508-7514.

87 Y. Yamada, M. Okamoto, K. Furukawa, T. Kato and K. Tanaka, Angew. Chem., Int. Ed., 2012, 51, 709-713.

88 D. C. Milan, M. Krempe, A. K. Ismael, L. D. Movsisyan, M. Franz, I. Grace, R. J. Brooke, W. Schwarzacher,
S. J. Higgins, H. L. Anderson, C. J. Lambert, R. R. Tykwinski and R. J. Nichols, Nanoscale, 2017, 9, 355361.

89 M. Mohankumar, M. Holler, E. Meichsner, J. F. Nierengarten, F. Niess, J. P. Sauvage, B. DelavauxNicot, E. Leoni, F. Monti, J. M. Malicka, M. Cocchi, E. Bandini and N. Armaroli, J. Am. Chem. Soc., 2018, 140, 2336-2347.

90 C. Schäfer, G. Ragazzon, B. Colasson, M. La Rosa, S. Silvi and A. Credi, ChemistryOpen, 2016, 5, 120-124.

91 I. Prigogine, Introduction to Thermodynamics of Irreversible Processes, Wiley, New York, USA, 3rd edn, 1968.

92 C. Pezzato, C. Cheng, J. F. Stoddart and R. D. Astumian, Chem. Soc. Rev., 2017, 46, 5491-5507.

93 M. R. Wilson, J. Sola, A. Carlone, S. M. Goldup, N. Lebrasseur and D. A. Leigh, Nature, 2016, 534, 235-240.

94 S. Erbas-Cakmak, S. D. P. Fielden, U. Karaca, D. A. Leigh, C. T. McTernan, D. J. Tetlow and M. R. Wilson, Science, 2017, 358, 340-343.

95 G. Ragazzon, M. Baroncini, S. Silvi, M. Venturi and A. Credi, Nat. Nanotechnol., 2015, 10, 70-75.

96 H. Logtenberg, J. Areephong, J. Bauer, A. Meetsma, B. L. Feringa and W. R. Browne, ChemPhysChem, 2016, 17, 1895-1901.

97 B. S. L. Collins, J. C. M. Kistemaker, E. Otten and B. L. Feringa, Nat. Chem., 2016, 8, 860-866.

98 C. Cheng, P. R. McGonigal, S. T. Schneebeli, H. Li, N. A. Vermeulen, C. Ke and J. F. Stoddart, Nat. Nanotechnol., 2015, 10, 547-553.

99 C. Pezzato, M. T. Nguyen, C. Cheng, D. J. Kim, M. T. Otley and J. F. Stoddart, Tetrahedron, 2017, 73, 4849-4857.

100 C. Pezzato, M. T. Nguyen, D. J. Kim, O. Anamimoghadam, L. Mosca and J. F. Stoddart, Angew. Chem., Int. Ed., 2018, 57, 9325-9329.

101 A. J. Avestro, D. M. Gardner, N. A. Vermeulen, E. A. Wilson, S. T. Schneebeli, A. C. Whalley, M. E. Belowich, R. Carmieli, M. R. Wasielewski and J. F. Stoddart, Angew. Chem., Int. Ed., 2014, 53, 4442-4449.

102 Y. Wang, M. Frasconi and J. F. Stoddart, ACS Cent. Sci., 2017, 3, 927-935.

103 H. V. Schröder and C. A. Schalley, Beilstein J. Org. Chem., 2018, 14, 2163-2185.

104 J. L. Zhang, J. Q. Zhong, J. D. Lin, W. P. Hu, K. Wu, G. Q. Xu, A. T. Wee and W. Chen, Chem. Soc. Rev., 2015, 44, 29983022.

105 W. Kaim and J. Fiedler, Chem. Soc. Rev., 2009, 38, 33733382. 